\title{
Extensions, Extra Factors, and Extreme Complexity: Ribosomal Structures Provide Insights into Eukaryotic Translation
}

\section{Melanie Weisser and Nenad Ban}

Institute of Molecular Biology and Biophysics, Department of Biology, ETH Zürich, 8093 Zürich, Switzerland

Correspondence: ban@mol.biol.ethz.ch

\section{SUMMARY}

Although the basic aspects of protein synthesis are preserved in all kingdoms of life, there are many important structural and functional differences between bacterial and the more complex eukaryotic ribosomes. High-resolution cryo-electron microscopy (cryo-EM) and X-ray crystallography structures of eukaryotic ribosomes have revealed the complex architectures of eukaryotic ribosomes and species-specific variations in protein and ribosomal RNA (rRNA) extensions. They also enabled structural studies of a range of eukaryotic ribosomal complexes involved in translation initiation, elongation, and termination, revealing unique mechanistic features of the eukaryotic translation process, especially with respect to the identification and recognition of translation start and stop codons on messenger RNAs (mRNAs). Most recently, structural biology has provided insights into the eukaryotic ribosomal biogenesis pathway by visualizing several of its complex intermediates. This review highlights the past decade's structural work on eukaryotic ribosomes and its implications on our understanding of eukaryotic translation.

\section{Outline}

1 Ribosomal architecture

2 Eukaryotic ribosomes-Extensions and expansions

3 The eukaryotic translation cycle

4 Eukaryotic translation initiation and reinitiation

5 Alternative translation initiation strategies
6 Eukaryotic translation elongation mechanisms

7 Eukaryotic translation termination and recycling

8 Eukaryotic ribosomal biogenesis

9 Future challenges

References

Editors: Thomas R. Cech, Joan A. Steitz, and John F. Atkins

Additional Perspectives on RNA Worlds available at www.cshperspectives.org

Copyright (C) 2019 Cold Spring Harbor Laboratory Press; all rights reserved; doi: 10.1101/cshperspect.a032367 


\section{RIBOSOMAL ARCHITECTURE}

Ribosomes translate the information encoded in messenger RNA (mRNA) to synthesize proteins from amino acids. They are large macromolecular ribonucleoprotein complexes (RNPs) composed of several chains of ribosomal ribonucleic acids (rRNAs) and many ribosomal proteins (r-proteins), which are organized in two subunits, a small and a large one that are named according to their ultracentrifugation sedimentation coefficients expressed in Svedberg units (S) (Fig. 1). The large ribosomal subunit (LSU) harbors the active site of the ribosome, the "peptidyl transferase center" (PTC), that catalyzes peptide bond formation between amino acids during protein synthesis, whereas the small ribosomal subunit (SSU) is responsible for binding and decoding of the mRNA in the decoding center.

The process of protein synthesis is facilitated by a number of protein factors and occurs in several stages-initiation, elongation, termination, and recycling - during which LSUs and SSUs can reversibly dissociate and reassociate. They interact via intersubunit bridges at the predominantly rRNA-based subunit interface (Ben-Shem et al. 2011). Early low-resolution structures showed that both subunits contain three transfer RNA (tRNA)-binding sites at the subunit interface, termed "A-" (aminoacylation), "P-" (peptidyl), or "E-" (exit) site (Fig. 1). Protein synthesis starts with binding of an initiator tRNA to the P-site of the ribosome where it interacts with the start codon on the mRNA. During elongation, an aminoacylated tRNA is delivered to the A-site. After the peptide bond formation reaction, it moves to the P-site with the whole nascent peptide chain attached to it and after the next round of peptide bond formation, the tRNA leaves the ribosome in the deacylated state via the E-site. During the decoding process, the codon-anticodon matching is facilitated and monitored on the SSU, whereas peptide bond formation and nascent peptide exit take place on the LSU. Thus, tRNAs bind to the intersubunit space with their anticodon stems attached to the A-, P-, or E-site of the SSU, whereas their aminoacylated acceptor CCA $3^{\prime}$ ends point toward the LSU.

The most fundamental and functionally important features of LSUs are the PTC and the polypeptide exit tunnel that extends from the PTC to the universally conserved $\mathrm{r}$ proteins uL23, uL29, and uL24 on the solvent-exposed side of the LSU (Ben-Shem et al. 2011; Klinge et al. 2011). Further characteristic features are the central protuberance (CP; including r-proteins uL18/uL5), the L1 stalk (including $\mathrm{uL} 1)$ that coordinates the expulsion of E-site tRNAs from the ribosome, and the P1/P2 stalk and the sarcin-ricin loop (SRL) responsible for the recruitment and activation of ribosome-dependent guanosine triphosphatases (GTPases) to the ribosome (Fig. 1) (Diaconu et al. 2005; Voorhees et al. 2010; Ben-Shem et al. 2011).
The architecture of the SSU is marked by the groove of the mRNA channel, which divides the subunit into a "head" and a "body" domain (Wimberly et al. 2000; Rabl et al. 2011; Hussain et al. 2014). mRNAs enter the channel between the "beak" structure of the SSU head and the "shoulder" of the SSU body, in which r-proteins with intrinsic helicase activity or associated adenosine triphosphate (ATP)-driven RNA helicases unwind possible mRNA secondary structures (Takyar et al. 2005; Hashem et al. 2013a). After passing the so-called "mRNA entry latch" (Zhang et al. 2015), which can close and stabilize mRNAs inside the channel, mRNAs reach the decoding center of the SSU A-site where the base-pairing of an mRNA codon with an anticodon of incoming tRNAs takes place (Hussain et al. 2014; Shao et al. 2016). Finally, mRNAs exit the ribosome near the SSU E-site at the SSU "platform," formed by the central SSU rRNA domain and r-proteins (Fig. 1).

\section{EUKARYOTIC RIBOSOMES-EXTENSIONS AND EXPANSIONS}

Structural analysis of bacterial ribosomes by X-ray crystallography and electron microscopy has played an important role in revealing ribosomal architecture, thereby providing key insights into the mechanisms that underlie the translation process. High-resolution X-ray structures have shown the central role of rRNA in the selection of cognate tRNAs in the decoding center (Wimberly et al. 2000) and revealed that the PTC is exclusively composed of rRNA, which provided experimental proof that ribosomes are "ribozymes" and evolutionarily stem from an early RNA-based world (Nissen et al. 2000; Schmeing and Ramakrishnan 2009; Klinge et al. 2011).

Early structural research on ribosomes has been covered by many excellent reviews and book chapters (e.g., Schmeing and Ramakrishnan 2009; Voorhees and Ramakrishnan 2013), but predominantly focused on bacterial translation systems. Therefore, this review will focus on eukaryotic translation and the high-resolution structures of eukaryotic ribosomal complexes that became available in recent years.

Eukaryotic ribosomes have a molecular mass of $\sim 4.3$ $\mathrm{MDa}$ and a sedimentation coefficient of $80 \mathrm{~S}$ and are therefore considerably larger than bacterial $70 \mathrm{~S}$ ribosomes with a molecular mass of $\sim 2.3 \mathrm{MDa}$ (Melnikov et al. 2012). Eukaryotic SSU and LSU sediment at 40S and 60S (Klinge et al. 2011; Rabl et al. 2011), whereas bacterial ribosomal subunits sediment at 30S and 50S, respectively (Wimberly et al. 2000; Melnikov et al. 2012).

The first high-resolution crystal structures of eukaryotic ribosomes revealed how complex eukaryotic cytoplasmic ribosomes are in comparison with their bacterial and archaeal counterparts, with archaeal ribosomes representing 

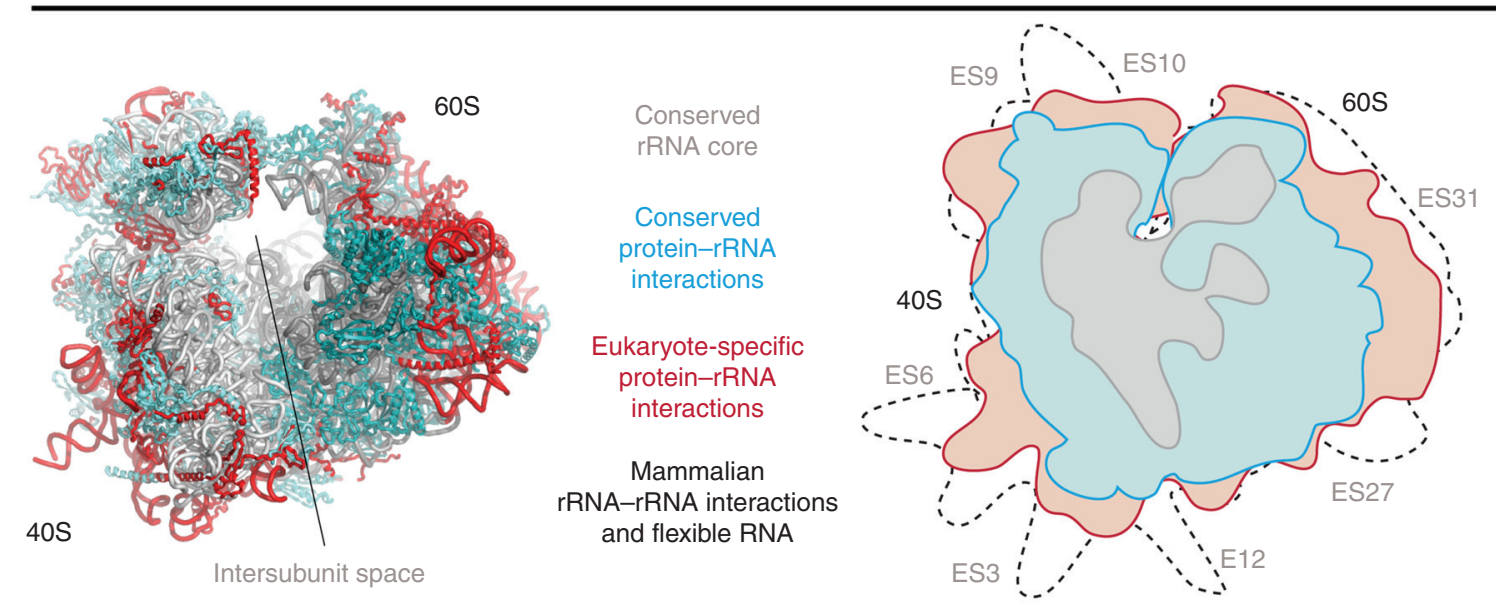

Small ribosomal subunit (40S)


Figure 1. The eukaryotic 80 Svedberg unit (S) ribosome consists of a $40 \mathrm{~S}$ and a $60 \mathrm{~S}$ subunit. The $40 \mathrm{~S}$ consists of an $18 \mathrm{~S}$ rRNA (gray) and 33 proteins (cyan), whereas the 60 S contains 5S, 5.8S, and 28S rRNA (gray) and 47 proteins (cyan). Eukaryotes have evolved eukaryote-specific proteins, protein extensions, and rRNA expansion segments (ESs) (red), with metazoans and particularly mammals displaying the greatest extent of complexity and ES length. As a result of this evolutionary process, eukaryotic ribosomes have a characteristic layered architecture (top right panel). The universally conserved ribosomal core is rRNA-based (gray) and wrapped in a conserved layer of ribosomal protein (r-protein) and rRNA interactions (cyan), which in eukaryotes is surrounded by an additional layer of eukaryotespecific r-protein-rRNA interactions (red). Because of their especially elongated ESs, mammals display an extra outer layer of rRNA-rRNA interactions between ESs and a periphery of flexible, tentacle-like ES extensions (black dotted lines). Both $40 \mathrm{~S}$ and $60 \mathrm{~S}$ are marked by characteristic conserved architectural landmarks (lower panel). Transfer RNAs (tRNAs) bind to ribosomal A- (aminoacylation), P- (peptidyl), and E- (exit) sites that are located on the subunit interface of both subunits. The small ribosomal subunit (SSU) can be divided into a head (with a beak) and a body with a platform, shoulder, left foot (LF), and right foot (RF). The large ribosomal subunit (LSU) has three characteristic lobes: the central protuberance (CP), the L1 stalk, and the P stalk, below which the guanosine triphosphatase (GTPase)-activating sarcin-ricin loop (SRL) is located. 
an evolutionary intermediate (Ben-Shem et al. 2011; Klinge et al. 2011; Rabl et al. 2011). Despite the overall high degree of conservation of the rRNA core and the existence of a universally conserved set of r-proteins, eukaryotic ribosomes display eukaryote-specific proteins, eukaryotespecific tails, and extensions to the universally conserved r-protein cores, as well as eukaryote-specific rRNA insertions termed rRNA expansion segments (ESs), all of which localize mostly to the solvent-exposed face of the eukaryotic LSU and to the head of the eukaryotic SSU with the exception of the highly conserved tunnel exit area (Fig. 1). To rationalize these differences, a new nomenclature for ribosomal proteins was introduced, indicating whether an $\mathrm{r}$-protein is universally conserved (uS/uL), specific for bacteria $(\mathrm{bS} / \mathrm{bL})$ or uniquely exist in eukaryotes (and archaea) (eS/eL) (Klinge et al. 2011; Ban et al. 2014).

Since these first breakthroughs, many high-resolution structures of ribosomes from different eukaryotic species have become available because of the technological and methodological advances in the field of cryo-electron microscopy (cryo-EM) (Bai et al. 2015). Structures of plant (Gogala et al. 2014), insect (Anger et al. 2013), pathogenic protozoa (Sun et al. 2015), kinetoplastid (Gao et al. 2005; Hashem et al. 2013; Shalev-Benami et al. 2016), yeast (BenShem et al. 2011), ciliate (Klinge et al. 2011; Rabl et al. 2011), and mammalian ribosomes (Anger et al. 2013; Voorhees et al. 2014) have shown that even among eukaryotic species, which, except for yeast, all contain the same set of 80 r-proteins, ribosomes can differ significantly in their r-protein sequences and the length of rRNA ESs (Melnikov et al. 2012). This variability is further increased by the posttranslational modifications of $r$-proteins, differential expression levels of r-proteins, and the existence of r-protein paralogs, which indicate that specialized ribosomes could occur within different tissues, life cycles, and metabolic or developmental stages within the same organism (reviewed in Xue and Barna 2012).

With the exception of kinetoplastid ribosomes (Gao et al. 2005; Hashem et al. 2013; Shalev-Benami et al. 2016), metazoan and specifically mammalian ribosomes (Anger et al. 2013; Voorhees et al. 2014) are on average more com- plex and larger than protozoan ribosomes (Ben-Shem et al. 2011; Klinge et al. 2011; Rabl et al. 2011), which is in part attributable to an increase of mass on the protein level, but particularly to larger rRNA ESs.

Interestingly, these extra protein extensions can be found at functionally important ribosomal sites. On the LSU, extensions mainly affect regions in the vicinity of the L1 and P stalks and the peptide tunnel exit (eL22 and uL23 in Drosophila; Anger et al. 2013). On the SSU, changes are most pronounced at the mRNA channel entry and exit areas (eS26; Anger et al. 2013) where they are likely to have an effect on the binding of ribosome-associated factors and mRNAs.

Because the ESs are able to protrude like tentacles beyond the conserved layer of protein-rRNA interactions, they add an additional rRNA-based outer layer to metazoan ribosomes (Anger et al. 2013). The result is a characteristic layered architecture of cytosolic eukaryotic ribosomes (Fig. 1): The innermost core is rRNA-based and universally conserved. It is wrapped into a layer of universally conserved protein-rRNA interactions surrounded by an even more intricate network of eukaryote-specific protein-rRNA interactions followed by an outermost layer of metazoanspecific RNA-RNA inter-ES contacts and a periphery of flexibly protruding ES tips (Anger et al. 2013).

\section{THE EUKARYOTIC TRANSLATION CYCLE}

Because eukaryotic cytoplasmic ribosomes have long halflives of several days (Nikolov et al. 1983) they are capable of translating many mRNAs during their life span. On each mRNA, they proceed through a four-stage translation cycle: The determination of the correct open reading frame (ORF) on an mRNA (initiation), repetitive cycles of peptide bond formation between amino acids (elongation), and the recognition of the end of the ORF (termination) when the ribosome is released from the mRNA (ribosomal recycling) allowing it to initiate another translation cycle (Fig. 2).

At each of the four stages, different regulatory translation initiation, elongation, or release factors associate with

Figure 2. The eukaryotic translation cycle. Ribosomal biogenesis (lavender) starts in the nucleolus and ends in the cytoplasm, where mature translation-competent cytoplasmic eukaryotic $40 \mathrm{~S}$ and $60 \mathrm{~S}$ ribosomal subunits are being released. Ribosomal protein translation proceeds in cycles of four stages: translation initiation (red), elongation (yellow), and termination (blue) followed by ribosomal recycling (green). During initiation, the SSU attaches to an mRNA, either via the canonical (eIF1-5) eukaryotic translation initiation factor-dependent pathway or via alternative eIF2D/malignant T-cell amplified protein 1 (MCT-1)/density-regulated protein (DENR) or internal ribosomal entry site (IRES)-mediated (re-) initiation, whereas the $60 \mathrm{~S}$ ribosomal subunit is prevented from premature reassociation with the 40 S by eIF 6 until the correct start codon has been recognized by the initiator tRNA. Then, the two subunits associate and the $80 \mathrm{~S}$ ribosome translates the open reading frame (ORF) of the mRNA in repetitive cycles of elongation/ translocation until it either stalls prematurely in case of a truncated mRNA, which triggers the Hbs1-Pelota-dependent rescue pathway, or at a normal stop codon, leading to translation termination. (Legend continues on following page.) 
Eukaryotic translation cycle

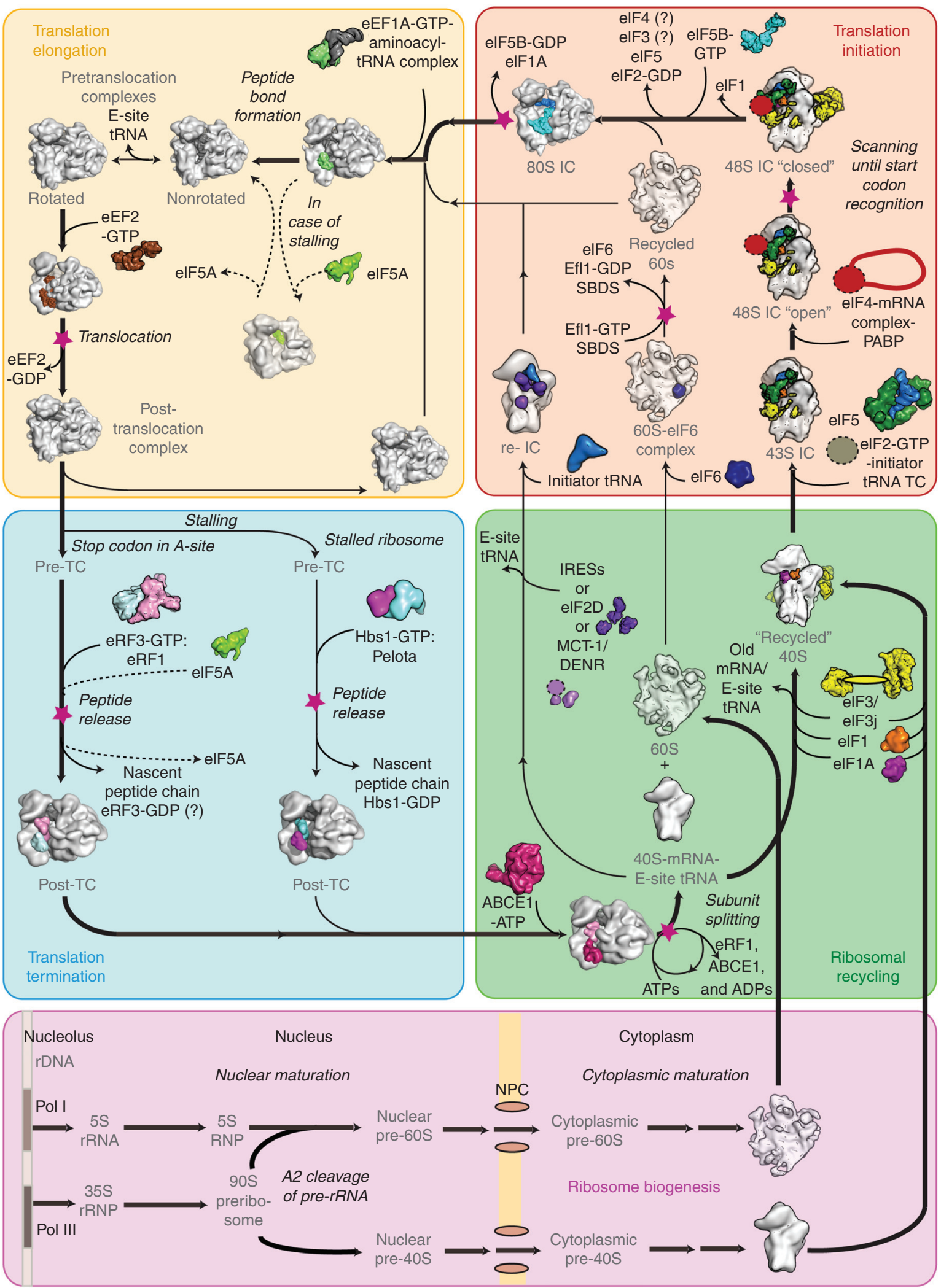

Figure 2. (Legend continued from previous page.) In both cases, the ribosomal subunits are being split by the ATPase ABCE1 and detached from mRNA and remaining deacylated tRNAs, such that they can engage in another round of translation initiation on either the same or a different mRNA. Some translation factors act as GTPases, which catalyze GTP-dependent reactions and therefore mark energy-consuming irreversible checkpoints along the trajectory of the translational cycle ( pink stars). IC, initiation complex. 
the ribosome catalyzing the delivery of tRNAs, the binding and unwinding of the mRNA, and the translocation or splitting of the ribosomal subunits. Some of these factors act as GTPases, which catalyze GTP-dependent reactions and mark irreversible checkpoints along the trajectory of the translational cycle (Fig. 2).

Translation can also proceed via alternative routes depending on the presence of short regulatory nonprotein-coding upstream open reading frames (uORFs) or structured cis-regulatory elements (IRESs, internal ribosomal entry sites) in the $5^{\prime}$ untranslated region ( $5^{\prime}$ UTR) of an mRNA. Moreover, ribosomal stalling during translation elongation or termination caused by the occurrence of rare codons in the ORF (Melnikov et al. 2016) or the recognition of truncated mRNAs without a stop codon will trigger alternate ribosomal rescue pathways (Fig. 2) (van den Elzen et al. 2014).

\section{EUKARYOTIC TRANSLATION INITIATION AND REINITIATION}

The eukaryotic translation cycle starts with translation initiation on the SSU, after the subunits have been split during the preceding ribosomal recycling stage (Figs. 2 and 3 ). Initiation involves three critical steps: (1) Methionylated initiator tRNA is recruited to the SSU P-site. This leaves the A-site free for the subsequent entry of the first postinitiation aminoacyl elongator tRNA. (2) The SSU binds mRNA and scans for the start codon, whereby AUG triplets have universally evolved as the most frequently used start codon. (3) After accommodating initiator tRNA to establish start codon-anticodon interactions in the P-site, the LSU joins the SSU to form an elongation-competent mRNAbound ribosome.

In eukaryotes, all three events are mediated and regulated by at least 12 accessory eukaryotic translation initiation factors (eIFs), many of which are complex multidomain or multisubunit proteins (Voigts-Hoffmann et al. 2012). In contrast, three initiation factors (IFs) suffice during prokaryotic translation initiation. One of the reasons for the use of these extra factors in eukaryotes lies in the different characteristics of prokaryotic and eukaryotic mRNAs (reviewed in Hinnebusch 2011, 2014). Standard eukaryotic mRNAs possess a 100-200-nt-long 5' UTR (Pesole et al. $2001)$ to which a $5^{\prime} 7$-methylguanosine $(\mathrm{m} 7 \mathrm{G})$ cap is attached and a $3^{\prime}$ UTR in which a poly(A) tail is posttranscriptionally added to protect the mRNA against premature nucleolytic degradation. Both features are recognized by eIFs to select intact mRNAs (reviewed in Hinnebusch 2011). Moreover, eukaryotic 5' UTRs lack a Shine-Dalgarno sequence that is frequently used in prokaryotes to position the mRNA with the start codon in the P-site of the SSU.
Thus, mRNA affinity for the eukaryotic initiation complex (IC) as well as the start codon selection rely predominantly on the nucleotide sequence, secondary structure, and accessibility of the start codon. These features are altogether referred to as the optimal start codon context (Kozak 1986), an example of which is the "Kozak consensus sequence" (5'(A/G)NNAUGG-3') in mammals (Kozak 1986). However, eukaryotic SSUs do not immediately bind in the vicinity of the start codon, instead, they "scan" for it moving along the mRNA in a $5^{\prime}$ to $3^{\prime}$ direction with an initiator tRNA bound to their P-sites. Upon recognizing the start codon, the tRNA is accommodated and the SSU closes down on the tRNA and stops scanning (reviewed in Hinnebusch 2011, 2014).

$5^{\prime}$-UTR scanning is a eukaryote-specific feature of translation initiation and it starts with the binding of eIF1, eIF1A, and eIF3 during the transition from ribosomal recycling to initiation (Fig. 3A). Crystal structures of a 40SeIF1 (Rabl et al. 2011) and 40S-eIF1-eIF1A complexes (Lomakin and Steitz 2013; Weisser et al. 2013), as well as a cryo-EM map of a 40S-eIF1-eIF1A-eIF3j assembly (Aylett et al. 2015), have shown that eIF1 binds to the vicinity of the SSU P-site and is sterically incompatible with $60 \mathrm{~S}$ association, whereas eIF1A blocks the A-site for tRNA binding (Lomakin and Steitz 2013) (Fig. 3A, close-up). eIF1 bears no homology with any bacterial IF, whereas eIF1A is the homolog of bacterial IF1, yet possesses eukaryote-specific long flexible carboxy-terminal and amino-terminal tails (CTT and NTT). Together with eIF3, a multisubunit protein (Hashem et al. 2013a,b; Erzberger et al. 2014; Aylett et al. 2015) that spans the solvent-exposed side of the $40 \mathrm{~S}$ subunit and binds both the mRNA entry and exit channel areas (Erzberger et al. 2014; Aylett et al. 2015), eIF1 and eIF1A stabilize SSUs in an "open" conformation with a swiveled-up 40S head position permissive for mRNA exchange at the channel (Pestova and Kolupaeva 2002; Llácer et al. 2015). Mammalian eIF3 contains 11-13 subunits (eIF3a-eIF3m), whereas several yeast eIF3 complexes possess only six conserved core subunits (eIF3a, b, c, g, I, and j) (Fig. 3A, close-up).

In combination, eIF1, eIF1A, and eIF3 promote mRNA and tRNA release from previously used 40S ribosomal subunits and the subsequent formation of the " $43 \mathrm{~S}$ pre-initiation complex" (43S PIC) by stabilizing the 40S ribosomal subunit in a conformation with an increased affinity for eIF2 and eIF5 (Olsen et al. 2003). eIF2 is a GTPase composed of three $(\alpha, \beta$, and $\gamma)$ subunits. They bind eukaryotic initiator tRNA and deliver it to the SSU in the form of a ternary eIF2-GTP-initiator tRNA complex (Schmitt et al. 2010). eIF5 is a two-lobed protein with a carboxy-terminal domain (CTD) and an amino-terminal domain (NTD) connected by a flexible linker (Bieniossek et al. 2006), which acts as the GTPase-activating protein (GAP) of eIF2, carry- 
A
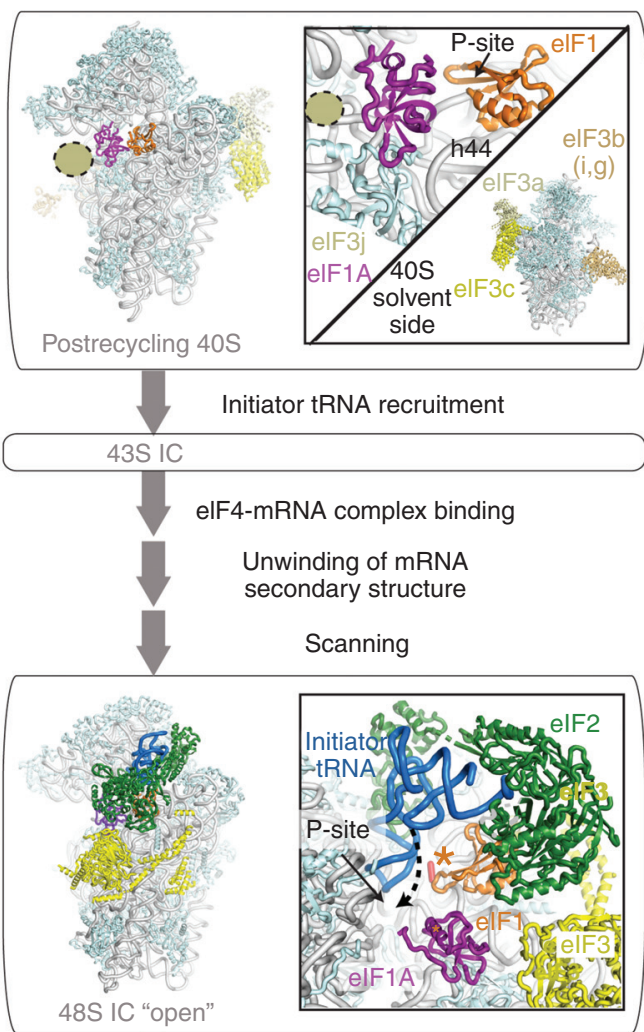

48S IC "open"

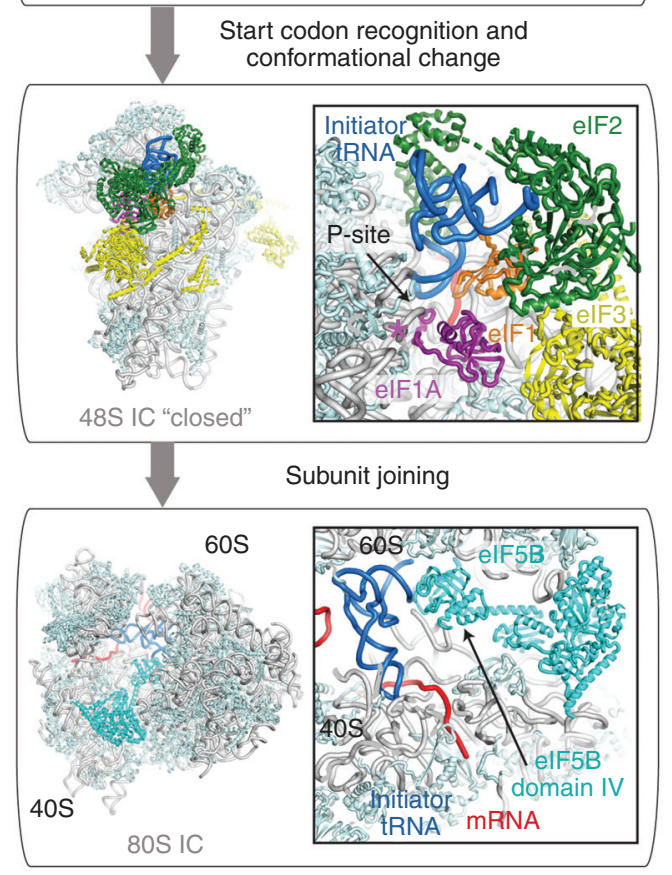

B Translation reinitiation

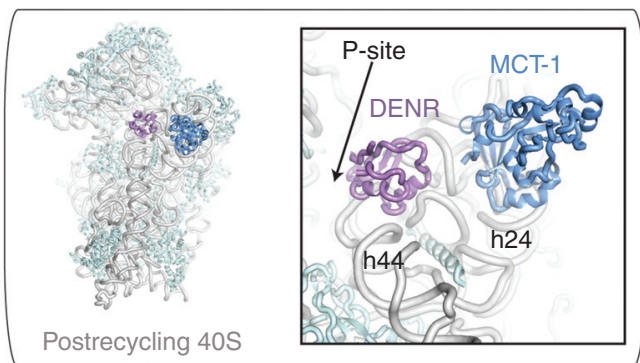

Postrecycling 40S no new mRNA binding and scanning, start codon recognition

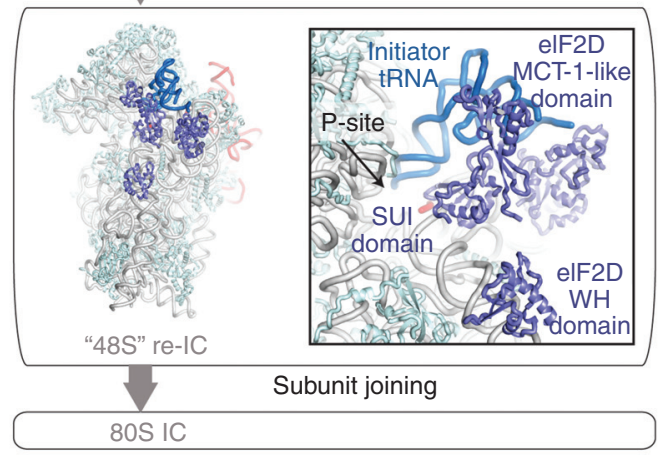

Examples of

C IRES-mediated initiation
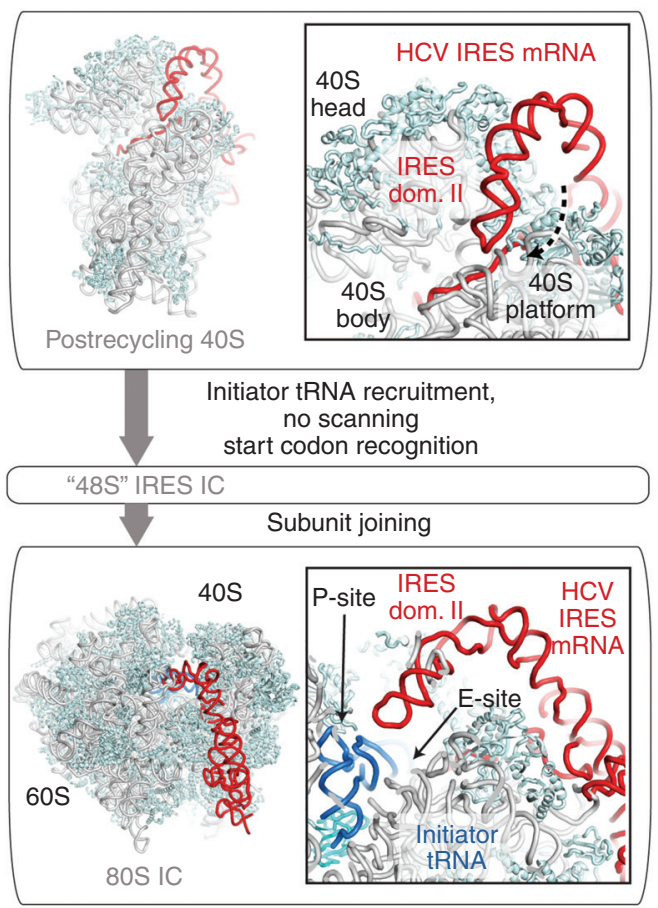

Figure 3. Eukaryotic translation initiation. (A) Classical eukaryotic translation initiation starts after subunit splitting with the assembly of eIF1, eIF1A, and eIF3 on the $40 \mathrm{~S}$ ribosomal subunit and proceeds with the recruitment of the

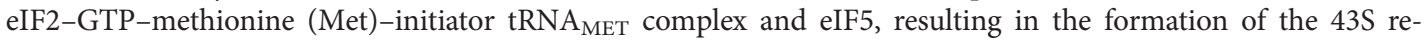
initiation complex (re-IC). After eIF4-mediated mRNA attachment, the open 48S IC is formed, which transitions to the closed $48 \mathrm{~S}$ complex on start codon recognition and proper accommodation of the initiator tRNA in the ribosomal P-site. Subsequent initiation factor dissociation allows eIF5B binding, eIF5B-eIF1A-mediated subunit joining, and formation of the 80S IC. (B) Alternatively, translation reinitiation after the translation of a short upstream open reading frame (uORF) can be mediated either by the MCT-1-DENR heterodimer or eIF2D or $(C)$ by IRESs like the hepatitis $\mathrm{C}$ virus IRES. 
ing a GTPase-activating arginine finger in its NTD (Das and Maitra 2001).

eIF2 $\gamma$ is the core subunit of eIF2 that harbors the GTPase activity (Roll-Mecak et al. 2004; Schmitt et al. 2012) and displays a typical three-lobed GTPase structure (Roll-Mecak et al. 2004; Schmitt et al. 2012). Domain II of eIF2 $\gamma$ recognizes terminally methionylated initiator tRNA through a conserved binding groove, inducing a characteristically kinked conformation in the initiator tRNA acceptor end (Schmitt et al. 2012). In contrast to prokaryotes that discriminate between methionylated initiator and elongator tRNAs through initiator tRNA methionine formylation, eIF2 $\gamma$ specifically recognizes a conserved Watson-Crick base pair between $\mathrm{Al}$ and $\mathrm{U} 72$ in eukaryotic initiator tRNAs, which does not exist in methionylated elongator tRNAs (Kapp et al. 2006). The eIF $2 \alpha$ and eIF $2 \beta$ subunits interact with the eIF $2 \gamma$ core, but not with each other, and contribute to initiator tRNA binding (Schmitt et al. 2012; Llácer et al. 2015).

The ternary complex of eIF2-GTP-initiator tRNA and eIF5 assemble simultaneously or successively with the 40SeIF1-eIF1A-eIF3 complex to form the 43S PIC. A highresolution structure of the $43 \mathrm{~S}$ PIC does not exist, but cryo-EM maps at lower resolutions have provided insights into its overall architectural features (Hashem et al. 2013). eIF $2 \alpha$ binds to the E-site of the SSU, analogously to the binding of E-site tRNA, whereas the ribosomal contacts for eIF2 $\gamma$ and eIF2 $\beta$ remain debated (Hussain et al. 2014; Llácer et al. 2015). Together, the three subunits position the initiator tRNA into the $40 \mathrm{~S} \mathrm{P}$-site, for which it has an increased affinity because of conserved interactions between three initiator tRNA-specific successive G:C base pairs (29:41, 30:40, and 31:39) in the tRNA anticodon stem loop with rRNA bases A790, G1338, and A1339 (bacterial numbering) of the SSU P-site (Korostelev et al. 2006; Kolitz and Lorsch 2010). In the absence of a start codon, the initiator tRNA adopts a partially accommodated metastable position in the P-site (termed "P $\mathrm{PUT}_{\text {T }}$ ") (reviewed in Hinnebusch 2011).

mRNA attachment causes the transition to an open $48 \mathrm{~S}$ complex and is thought to be mediated by the multisubunit initiation factor complexes eIF3 and eIF4F (Jivotovskaya et al. 2006). eIF4F preassembles onto the mRNA causing it to adapt a "closed loop" conformation by simultaneously interacting with both mRNA ends: One eIF4F subunit called eIF4E binds the eukaryote-specific mRNA m7G cap, whereas another eIF4F subunit called eIF4G contacts the mRNA poly(A) tail via PABP (poly(A)-binding protein) (Wells et al. 1998). Multiple interactions between eIF4F and eIF3 subsequently recruit the mRNA to the SSU-PIC (Villa et al. 2013); however, they have not been structurally visualized in the context of an active complex at high resolution.
With the initiator tRNA bound to the P-site in a $\mathrm{P}_{\text {OUT }}$ conformation (Fig. 3A, middle), the open $48 \mathrm{~S}$ complex starts to scan base per base along the mRNA to localize the correct start codon. Scanning is processive and occurs in a $5^{\prime}$ to $3^{\prime}$ direction at a speed of $\sim 8 \mathrm{nt} / \mathrm{sec}$ (Vassilenko et al. 2011). It is supported by several copies of eIF4F subunit eIF4A, an ATP-driven RNA helicase, and eIF4B (or its homolog eIF4H), a stimulator of eIF4A activity, which drive the unfolding of mRNA secondary structure. Scanning usually also requires the assistance of accessory ATP-dependent DEAD-box RNA helicases, like DHX29 (Pisareva et al. 2008 and reviewed in Marintchev 2013).

eIF4A-driven mRNA unwinding is not processive and most likely happens "upstream" (at the mRNA entry site of the SSU). In its ATP-bound state, the helicase associates with double-stranded mRNA, whereas its ADP-bound state possesses a lower mRNA affinity and dissociates. Multiple rounds of attachment and detachment thereby allow the helicase domains to unwind the mRNA into single strands. Yet, it remains to be fully investigated how the mRNA is threaded into the mRNA channel of the SSU and whether the 48S PIC could scan along the mRNA while the mRNA $5^{\prime}$ cap remains stably associated with the IF complex (reviewed in Marintchev 2013).

The existing cryo-EM structure of an open $48 \mathrm{~S}$ complex from yeast (Fig. 3A, middle) (Llácer et al. 2015) does not provide insights into this process because it was formed on a model mRNA oligonucleotide with a near-cognate start codon and does not contain eIF4F or accessory helicases. Still, it offers detailed insights into the three-dimensional arrangement of initiation factors eIF1, $1 \mathrm{~A}$, and 2 and, to some extent, also of eIF3 and eIF5. $48 \mathrm{~S}$ complex structures, as well as structures of the 40S-eIF1 and 40S-eIF1-eIF1A complexes, illustrate that in an open, scanning-competent 40S, the $\mathrm{P}$-site initiator tRNA is kept in a $\mathrm{P}_{\text {OUT }}$ position with full accommodation sterically hindered by eIF1 (Rabl et al. 2011) and the CTT of eIF1A (Pestova and Kolupaeva 2002; Yu et al. 2009). eIF1's basic $\beta 1$ loop protrudes into the mRNA channel and contacts the mRNA in the P-site (Martin-Marcos et al. 2013), thereby restricting the conformational space for codon-anticodon duplex formation (Hussain et al. 2014). Thus, eIF1 and the eIF1ACTT prevent premature initiator tRNA binding to near-cognate start codons and ensure the fidelity of start codon recognition (Pestova and Kolupaeva 2002). This was previously suggested by genetic studies in yeast, which identified Sui ${ }^{-}$(suppressor of initiation codon) mutations in eIF1 and in the eIF1A CTT that lead to an increase in leaky scanning (i.e., translation initiation on near-cognate start codons) (Cheung et al. 2007; Fekete et al. 2007; Lee et al. 2007).

Upon start codon recognition, the $48 \mathrm{~S}$ complex transitions into a "closed" conformation with a less strongly ro- 
tated 40S head that is lowered over the mRNA channel, clamping onto the mRNA (Fig. 3A, middle) (Llácer et al. 2015). Premature closing can result in initiation at a noncognate start codon, whereas inhibiting the transition to the closed conformation results in decreased translation initiation efficiency at correct start codons (reviewed in Hinnebusch 2011).

The structure of the closed $48 \mathrm{~S}$ complex (Fig. 3A, middle) (Hussain et al. 2014; Llácer et al. 2015) shows that the initiator tRNA has changed from its $\mathrm{P}_{\text {OUT }}$ to a stably bound $\mathrm{P}_{\mathrm{IN}}$ position and becomes anchored to the start codon in the ribosomal P-site (reviewed in Hinnebusch 2011), thereby ejecting eIF1 and the CTT of eIF1A from their initial positions (Cheung et al. 2007). Interestingly, the new deep insertion of the codon-anticodon duplex into the P-site of the closed $48 \mathrm{~S}$ complex is stabilized by interactions with the previously unstructured NTT of eIF1A (Hussain et al. 2014; Llácer et al. 2015). This supports results from yeast genetic studies, which identified mutations in the eIF1A NTT with $\mathrm{Ssu}^{-}$(suppressor of Sui ${ }^{-}$) phenotypes (Fekete et al. 2007; Saini et al. 2010).

eIF2 $\beta$ positions a helix-turn-helix motif and its zincbinding domain between the tRNA, eIF1, eIF1A, and eIF $2 \gamma$ and contacts the $40 \mathrm{~S}$ head across the mRNA channel. Its amino-terminal helix is stably anchored to the $\mathrm{G}$ domain of eIF2 $\gamma$ (Schmitt et al. 2012; Llácer et al. 2015). Nuclear magnetic resonance (NMR) and biochemical experiments revealed an intricate interaction network between eIF1, eIF2, and eIF5 (Reibarkh et al. 2008; Luna et al. 2012) and it was shown that overexpression of eIF5 promotes eIF1 dissociation from the IC (Nanda et al. 2009). Therefore, it was concluded that eIF5 and eIF1 might compete for binding to eIF2 $\beta$ (Luna et al. 2012). eIF1 dissociation allows eIF5 to adopt eIF1's original binding site next to eIF2 $\beta$ and positions the GTPase-activating NTD of eIF5 closer to the GTPase active site on eIF2, where it is stabilized through interactions with the repositioned CTT of eIF1A (Yu et al. 2009; Hussain et al. 2014). Although GTP hydrolysis on eIF2 may occur at earlier stages of initiation, the rearrangement of the eIF5 GAP domain possibly triggers phosphate release from eIF2 and thereby irreversibly commits the IC to translation (Algire et al. 2005; Cheung et al. 2007; Nanda et al. 2009). Conversely, failure to induce phosphate release after start codon "recognition" leads to a resumption of the scanning process (Terenin et al. 2016). By transitioning from the GTPto the guanosine diphosphate (GDP)-bound state, eIF2 loses affinity for the initiator tRNA and the IC and is released from the IC, likely together with eIF5, eIF3, and eIF4.

Dissociation of eIF2/eIF5 from the complex allows the ribosome-dependent GTPase eIF5B, the ortholog of bacterial IF2/archaeal aIF2, to bind to the 40S subunit interface. It interacts with the core of eIF1A via a binding site that also mediates the contact between IF1 and IF2 in bacteria, but also via a conserved DIDDI motif in the eukaryote-specific eIF1A-CTT (Olsen et al. 2003; Acker et al. 2006; Fringer et al. 2007).

A structure of a mammalian eIF5B-initiator tRNA 80S complex without eIF1A shows that eIF5B binds to the 40S in a similar position as EF-Tu, IF2, and EF-G (Fig. 3A, bottom) (Fernandez et al. 2013). Although it is not completely clear how the $60 \mathrm{~S}$ is recruited, it is known that eIF5B binding to the $40 \mathrm{~S}$ subunit accelerates $60 \mathrm{~S}$ association (Acker et al. 2006) and is dependent on both eIF1A (in particular the DIDDI motif) and eIF5B (Olsen et al. 2003; Fringer et al. 2007). In the $80 S$ context, the interaction with eIF5B domain IV prevents the CCA end from contacting the $60 \mathrm{~S}$ ribosomal P-site and the PTC, whereas the eIF5B G domain is positioned next to the ribosomal GTPase-activating center. GTP hydrolysis on eIF5B induces a conformational change within the IC that weakens eIF5B's affinity for the latter and ultimately leads to coupled release of eIF5B and eIF1A (Fringer et al. 2007). As a consequence, the initiator tRNA adapts a P/P state on the $80 \mathrm{~S}$ ribosome, which can thus enter translation elongation.

\section{ALTERNATIVE TRANSLATION INITIATION STRATEGIES}

The fact that eukaryotic mRNAs possess $5^{\prime}$ UTRs opens up additional possibilities for regulating translation initiation via characteristic sequences and structured regions upstream of the coding sequence (reviewed in Hinnebusch et al. 2016). One well-investigated example of such cis-regulatory mRNA elements is IRESs that confer the ability to bind to the ribosomal subunit in the absence of a cap-binding eIF4F complex (Walsh and Mohr 2011). IRESs were first identified in viruses, but in recent years have also been detected in $\sim 10 \%$ of all cellular mRNAs (Weingarten-Gabbay et al. 2016). Cap-independent translation initiation offers the possibility of maintaining normal translation efficiency even during cellular stress conditions, when eIF4F complex availability is down-regulated. Viruses make use of such alternative initiation strategies to escape the host cell stress response and bias the translation machinery toward preferential translation of viral transcripts.

Viral IRESs can be assigned into three classes based on their structure. Class I IRESs occur in viruses with a positive sense strand bicistronic RNA genome, where they precede the second ORF and are therefore also referred to as intergenic region IRESs (IGRs). IGRs mediate translation initiation in the absence of IFs, an AUG start codon, and cellular initiator tRNA, because they structurally mimic initiator tRNA binding (Costantino et al. 2008). Class II IRESs occur within RNA viruses with a positive sense strand genome like 
the hepatitis $\mathrm{C}$ virus (HCV) or the classical swine fever virus (CSFV). They bind directly to the 40 S via a pseudoknot-like structure in a cap-independent and scanning-free manner because the AUG start codon is positioned into the 40S Psite on IRES-40S binding (Quade et al. 2015), yet they require initiation factor eIF2 for initiator tRNA recruitment and eIF3 for efficient translation initiation (Otto and Puglisi 2004). Class III IRESs usually occur in picornaviruses and have canonical IF requirements except for subunits eIF4E and the amino-terminal third of eIF4G that does not contain the eIF3-binding site (Redondo et al. 2013).

High-resolution structures of the class II HCV-IRES bound to the eukaryotic ribosome have shown that it is structured into four domains (Fig. 3C). Domain IV contains the start codon, whereas domain III mediates the interaction with eIF3 and the binding to $40 \mathrm{~S}$ expansion segment ES7 and r-protein eS27 (Hashem et al. 2013; Quade et al. 2015), i.e., to a location that overlaps with eIF3's binding site on the 40S subunit. Domain II occupies a position typically occupied by the E-site tRNA or eIF2 $\alpha$ (Fig. 3C, close-up) and appears to be critical for late steps of the initiation process, such as eIF5-induced hydrolysis of eIF2-bound GTP and joining of the LSU (Locker et al. 2007). Mimicking tRNA, the tip of domain II (IIb) appears to induce a conformational change in the $40 \mathrm{~S}$, which induces eIF2 release and promotes a transition from translation initiation to elongation (Locker et al. 2007).

Apart from IRES elements, eukaryotic cells make use of short uORFs in the $5^{\prime}$ UTR to fine-tune the translation initiation efficiency at the main ORF (reviewed in Hellens et al. 2016). uORFs usually consist of 100 or fewer codons and occur in all eukaryotes (Hellens et al. 2016). They are found in $\sim 50 \%$ of all mammalian and $\sim 13 \%$ of all yeast mRNAs (Calvo et al. 2009; Lawless et al. 2009). One possible mechanism for how uORFs can regulate translation is through "reinitiation" at the downstream main ORF with the help of canonical IFs (reviewed in Jackson et al. 2012; Skabkin et al. 2013). Reinitiation depends on the probability of reacquiring a new eIF2-GTP-initiator tRNA ternary complex after termination, which is influenced by the distance between the uORF stop codon and the main ORF start codon. Reinitiation efficiency is also affected by the length and secondary structure of mRNA in the uORF (Poyry et al. 2004). How ribosomes would assemble and reassemble between termination at the uORF stop codon and the new initiation start codon remains to be fully investigated. However, it is clear that for successful reinitiation the ribosome would have to stay bound to the mRNA, which would presumably be facilitated by some of the IFs staying bound to the ribosome; possibly eIF3 and eIF4G (de Breyne et al. 2009; Mohammad et al. 2017; and reviewed in Poyry et al. 2004; Jackson et al. 2012; Skabkin et al. 2013).
An alternative route of translation reinitiation was revealed with the identification of alternative translation initiation factors eIF2D (ligatin) and the homologous heterodimeric complex of oncogenic MCT-1 (malignant T-cell amplified protein or multiple copies of T-cell lymphoma) and DENR (density-regulated protein) (Fig. 3B) (Skabkin et al. 2010; Schleich et al. 2014). Like eIF1, eIF1A, and eIF3 ( $j)$, they can release mRNA and deacylated tRNA from the 40S during ribosomal recycling (Skabkin et al. 2013).

eIF2D and MCT-1-DENR are also able to recruit initiator tRNA to a start codon that is positioned in the 40S Psite and to promote subunit joining and translation initiation in the absence of eIF1, eIF1A, eIF2, eIF5, or eIF5B (Skabkin et al. 2010). They are thus capable of mediating translation reinitiation and also referred to as reinitiation factors (Schleich et al. 2014). Given that stress-induced phosphorylation of canonical initiation factor eIF $2 \alpha$ reduces eIF2 ternary complex formation and sequesters eIF2 away from the ribosome, stress conditions could potentially favor reinitiation by alternative translation IFs by making ribosomal-binding sites and also initiator tRNAs available for the interaction with eIF2D, MCT-1-DENR or others.

Structures of the eIF2D- and MCT-1-DENR-containing ICs show that these re-initiation factors use several functional domains to position initiator tRNA in the Psite of the 40S subunit (Lomakin et al. 2017; Weisser et al. 2017). One of the domains binds to the $40 \mathrm{~S}$ eIF1-binding site at the top of helix 44 (Fig. 3B) (Rabl et al. 2011) from where it monitors start codon recognition in the 40S P-site and prevents the association of the LSU. Another domain of eIF2D or MCT-1 binds and stabilizes the single-stranded CCA end of the initiator tRNA via its conserved RNAbinding groove but does not appear to establish conserved interactions with the aminoacyl moiety (Weisser et al. 2017), in agreement with the observation that eIF2D can also recruit deacylated tRNAs.

\section{EUKARYOTIC TRANSLATION ELONGATION MECHANISMS}

Once the correct ORF has been established on an mRNA during translation initiation and the $80 \mathrm{~S}$ has been assembled with an initiator tRNA in the P-site, the elongation stage of the translation cycle starts. Polypeptide chain elongation by one amino acid requires three major steps that are highly conserved between prokaryotes and eukaryotes: (1) ternary complex recruitment to the ribosomal A-site and decoding, (2) peptide bond formation, and (3) subsequent translocation of the ribosome on the mRNA by one codon in $5^{\prime}$ to $3^{\prime}$ direction (reviewed in Voorhees and Ramakrishnan 2013). The eukaryotic ternary complex consists of the GTP-bound elongation factor eEF1A bound to an amino- 
acylated elongator tRNA (Crepin et al. 2014). It is recruited to the ribosome via the flexible domains of the $\mathrm{P} 1 / \mathrm{P} 2$ stalk and binds such that its GTPase domain interacts with the SRL on the 60S subunit. eEF1A positions the tRNA anticodon into the A-site of the 40S subunit for interactions with the mRNA codon. Upon formation of cognate codon-anticodon interactions, the rRNA in the decoding center changes conformation and causes a distortion of the tRNA into a strained "A/T" conformation (Fig. 4, top) (Shao et al. 2016).

Cognate tRNAs establish canonical complementary Watson-Crick base pairs with positions 1 and 2 of the mRNA codon, whereas position three is permissive for noncanonical wobble base pairs in accordance with the degenerate genetic code (Crick 1966). A1493 (bacterial numbering) from rRNA helix 44 of the $40 \mathrm{~S}$ subunit establishes conserved hydrogen bond interactions with the minor groove of the codon-anticodon duplex at position 1 ("A-minor motif") and G530 from rRNA helix 18, A1492, and uS12 interact with the minor groove of position 2 . The third, wobble position, is directly contacted by G530 and indirectly via a magnesium ion through uS12 (Ogle et al. 2001; Shao et al. 2016). These interactions energetically favor the binding of cognate tRNAs and a concerted conserved conformational change in the rRNA, referred to as "domain closure": On cognate codon recognition, the $40 \mathrm{~S}$ head tilts toward the shoulder and the mRNA channel, whereas the shoulder rotates inward toward helix 44 (Ogle et al. 2002; Schmeing and Ramakrishnan 2009; Shao et al. 2016). This repositions eEF1A's $G$ domain with respect to the SRL such that GTPase activation becomes possible and GTP hydrolysis is triggered. In its GDP-bound form, eEF1A loses its affinity for tRNAs and the ribosome, and dissociates from the complex (Voorhees and Ramakrishnan 2013; Shao et al. 2016). Noncognate tRNAs will be rejected because their accommodation will be energetically less favorable. They either do not trigger domain closure and GTP hydrolysis in the first place or they dissociate from the ribosome because their binding affinity for the ribosome and the mismatched codon is low (Shao et al. 2016).

After its release from eEF1A, the aminoacyl A-site tRNA relaxes from its constrained $\mathrm{A} / \mathrm{T}$ conformation to allow the full accommodation of the A-site tRNA's aminoacylated end in the PTC of the 60S subunit (A/A state). There it interacts with the A-loop in an "induced fit" manner such that it is optimally positioned for nucleophilic attack of the P-site peptidyl-tRNA aminoacyl ester (Schmeing et al. 2005). eEF1A dissociation and tRNA accommodation are also accompanied by a characteristic eukaryote-specific rotation of the SSU around its longitudinal axis in the direction of the 60S L1 stalk. This movement is termed "subunit rolling" and is important for the subsequent tRNA repositioning (Budkevich et al. 2014). The resulting pretransloca- tion complexes predominantly adopt classical, nonrotated conformations with tRNAs being in $\mathrm{A} / \mathrm{A}, \mathrm{P} / \mathrm{P}$, and (in case of an existing E-site tRNA) E/E states (Fig. 4, upper middle) (Budkevich et al. 2011, 2014; Svidritskiy et al. 2014).

Once peptide bond formation has occurred, the nascent polypeptide chain is transferred to the A-site tRNA and the deacylated tRNA resides in the P-site. This allows repositioning of both tRNA acceptor arms with respect to the LSU, whereas their anticodon stems remain in position on the SSU. Because tRNA and intersubunit movements are coupled, the repositioning of the tRNAs is accompanied by a rotation of the SSU by $\sim 10^{\circ}$ with respect to the LSU, referred to as the "rotated state" (Agirrezabala et al. 2008). For both the unrotated and the rotated states, different conformations, "1 and 2," have been observed (Budkevich et al. 2011, 2014). Rotated states 1 and 2 differ in their tRNA positions, displaying tRNAs in $\mathrm{A} / \mathrm{A}$ and $\mathrm{P} / \mathrm{E}$ states or in $\mathrm{A} / \mathrm{P}$ and $\mathrm{P} / \mathrm{E}$ states (Fig. 4, upper middle) (Agirrezabala et al. 2008; Budkevich et al. 2011, 2014). Subunit rotation promotes the loss of an existing E-site tRNA because its affinity for the ribosome is lowered when the contact with the $60 \mathrm{~S}$ E-site is lost. At the same time, the rotated state allows an inward movement of the L1 stalk, providing stabilizing interactions for the P/E-tRNA (Fig. 4, upper middle) (Fei et al. 2008).

To allow the elongation of the nascent polypeptide chain by another amino acid, the ribosome has to free the A-site for the delivery of the next aminoacyl-tRNA and translocate by one codon on the mRNA. The precise mechanism of mRNA movement has not been elucidated, but it appears to be coupled to tRNA movement in terms of step size because experiments with quadruplet tRNA anticodons promoted translocation by four instead of three nucleotides (reviewed in Voorhees and Ramakrishnan 2013).

In vivo, translocation is catalyzed by a multidomain GTPase called eEF2 (Spahn et al. 2004). Like the other ribosome-dependent GTPases, eEF2 binds the ribosome in its GTP-bound state and in an elongated conformation with its G domain next to the SRL of the 60S subunit (Fig. 4, lower middle) (Spahn et al. 2004; Anger et al. 2013; Voorhees et al. 2014). eEF2 binding causes a characteristic ribosomal movement: The SSU head "swivels" up to $20^{\circ}$ and opens up the mRNA channel around the P- and E-sites of the SSU, which is a prerequisite for unrestricted tRNA/ mRNA movement during translocation (Spahn et al. 2004; Ratje et al. 2010). Swiveling induces a repositioning of tRNAs because tRNAs establish interactions with the $\mathrm{P}$ - and E-site elements of the body of the SSU while still maintaining contacts with $\mathrm{A}$ - and $\mathrm{P}$-site elements of the head (termed chimeric ap/P-pe/E states) (Ratje et al. 2010).

Upon GTP hydrolysis eEF2 relaxes into its GDP-bound conformation (Taylor et al. 2007), causing the ribosome to 


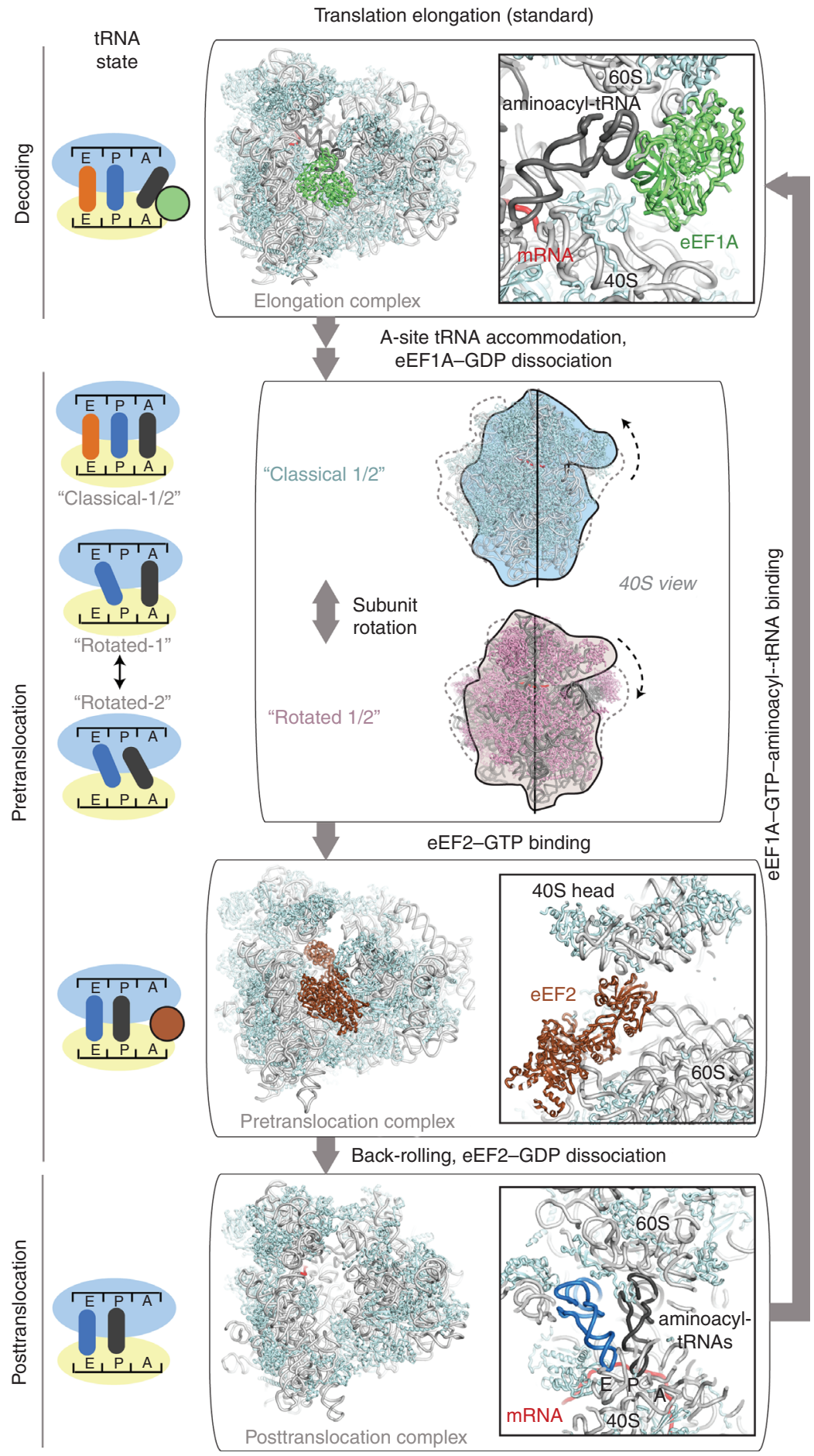

Figure 4. Eukaryotic translation elongation. For each mRNA codon within the open reading frame, an aminoacylated tRNA is delivered to the $80 \mathrm{~S}$ ribosome A-site in a ternary complex with GTP-bound elongation factor eEF1A, initially adopting a strained A/T tRNA state (top panel). If cognate tRNA binding is verified through hydrogen bond interactions in the A-site decoding center of the 40S, the A-site tRNA fully accommodates (adopting an A/A tRNA state), whereas GTP hydrolysis by eEF1A promotes the factor's release from the complex. The pretranslocation complex can exist in rotated and nonrotated (classical) subunit conformations, from which the rotated conformation allows tRNAs to move more freely between the subunits and adopt hybrid tRNA states (A/P and P/E) (upper middle panel). Also, it is preferentially bound by the translocation factor GTPase eEF2. GTP hydrolysis by eEF2 couples a conformational relaxation in the factor with subunit back-rotation, promoting a tRNA-coupled mRNA movement by one base triplet on the ribosome (lower middle panel). After eEF2-GDP release, tRNAs adopt classical P/P and E/E states in the posttranslocation complex, freeing the A-site for another round of eEF1A-mediated aminoacyl tRNA recruitment (bottom panel). 
revert back into a classical nonrotated posttranslocation state with peptidyl P/P-RNA and deacylated E/E-tRNA (Fig. 4, lower middle) (Budkevich et al. 2014; Svidritskiy et al. 2014 and reviewed in Voorhees and Ramakrishnan 2013). As soon as inorganic phosphate is released, eEF2GDP dissociates from the ribosome, vacating the ribosomal A-site for binding of the next eEF1A-aminoacyl-tRNA ternary complex and the start of another round of elongation/translocation (Taylor et al. 2007).

\section{EUKARYOTIC TRANSLATION TERMINATION AND RECYCLING}

Once a stop codon reaches the A-site of a translating ribosome, it is recognized by eukaryotic release factor 1 (eRF1) instead of by the eEF1A-aminoacyl-tRNA complex. Eukaryotic termination relies on only one class I release factor, eRF1, a protein of three (N, M, and C) domains that shares no sequence homology with bacterial class I release factors RF1 and RF2, but functions similarly. In contrast to RF1/RF2, eRF1 recognizes all three types of stop codons (Brown et al. 2015). In solution, eRF1 adopts an extended conformation, but when bound to the ribosome-dependent GTPase eRF3, which is the equivalent of prokaryotic RF3, it adopts a compact fold suitable for efficient binding of the 40S subunit (Alkalaeva et al. 2006).

Association of the eRF1-eRF3-GTP ternary complex with the ribosome allows eRF3 to contact the ribosomal GTPase-binding site, whereas eRF1 binds analogously to an A-site tRNA (Fig. 5A, top) (Preis et al. 2014; Brown et al. 2015). The tip of the eRF1 $\mathrm{N}$ domain reaches into the A-site, where it induces a conformational change in the $18 \mathrm{~S}$ rRNA of the 40S that compacts the mRNA and fixes the stop codon bases in defined positions, in which they can engage in a conserved hydrogen bonding network with eRF1. Structures of mammalian eRF1/eRF3 termination complexes bound to the three standard stop codons (UAG, UAA, and UGA) revealed how eukaryotes discriminate against nonstop codons (Brown et al. 2015). In contrast to the recognition of stop codons by prokaryotic RF1/RF2, eRF1 contacts stop codons via three previously identified conserved sequence motifs (GTS, NIKS, and YxCxxxF) and glutamate residue 55 (Glu55). Whereas purine residues and cytidines at position 1 are discriminated against by steric and hydrogen bonding requirements of the NIKS motif, respectively, bases at positions 2 and 3 can be recognized only at their Watson-Crick interface through hydrogen bonds with Glu55 if they are both purines, but not consecutive guanosines (Brown et al. 2015).

When eRF1 recognizes a stop codon, a conformational change occurs in the ribosome that stimulates eRF3's GTPase activity and ultimately leads to the dissociation of
eRF3 (reviewed in Jackson et al. 2012). Upon eRF3 release, full accommodation of eRF1 becomes possible such that the eRF1 M domain can reach deeper into the PTC on the 60S subunit (Shao et al. 2016). As in RF1/RF2, this domain carries a conserved GGQ motif that mediates peptide release by promoting the hydrolysis of the ester that connects the polypeptide chain to the P-site tRNA (Frolova et al. 1999). eRF1's peptide release activity is stimulated by ABCE1, the eukaryotic recycling factor equivalent, which binds to SSU of the posttermination complex once that eRF3 has dissociated (Fig. 5A, middle) (Brown et al. 2015; Shao et al. 2016). Consequently, eRF1 acts as a binding platform for ABCE1 and enhances ABCE1's intrinsically low NTPase activity (reviewed in Jackson et al. 2012). Therefore, eukaryotic translation termination is coupled to ribosomal recycling and the directionality of both processes is guaranteed by the fact that ABCE1 and eRF3 are mutually exclusive and that ABCE1 does not bind vacant ribosomes (Pisarev et al. 2010). ATP hydrolysis by ABCE1 is coupled to a conformational change of the conserved rRNA-binding iron-sulfur (Fe-S) cluster domain of ABCE1 (Fig. 5A, bottom close-up) (Pisarev et al. 2010; Brown et al. 2015). This conformational change likely causes subunit splitting and subsequent release of ABCE1 and eRF1 (Fig. 5A, bottom) (Heuer et al. 2017b).

Subsequently, the translation initiation or reinitiation factor binding to the SSU facilitates the detachment of the translated mRNA, displacement of the remaining deacylated tRNA, and the transition to translation initiation on a new mRNA (Skabkin et al. 2013 and reviewed in Jackson et al. 2012). Premature reassociation of the SSU and the LSU is sterically prevented by eIF1 bound to the $40 \mathrm{~S}$ and by eIF6 bound to the 60S (Klinge et al. 2011; Rabl et al. 2011).

Although eRF1/eRF3 catalyze termination on classical stop codons, the release factor paralogs Pelota (Dom34 in yeast)/Hbs1 evolved as mediators of premature translation termination on stalled mRNAs or mRNAs without a stop codon triggering "no-go decay" or "nonsense-mediated decay" pathways (Fig. 5B) (Kobayashi et al. 2010; Shao et al. 2016).

\section{EUKARYOTIC RIBOSOMAL BIOGENESIS}

Assembly and maturation of eukaryotic ribosomes are much more complex than in the case of prokaryotic ribosomes. The highly regulated process starts with the transcription of ribosomal pre-rRNA in the nucleolus and subsequently involves more than 200 assembly factors, including export factors, chaperones, and nucleases (reviewed in Gerhardy et al. 2014). The pre-rRNAs are transcribed by two polymerases: RNA polymerase I produces a $35 \mathrm{~S}$ prerRNA transcript (yeast nomenclature), which comprises 
Downloaded from http://cshperspectives.cshlp.org/ on April 26, 2023 - Published by Cold Spring Harbor Laboratory Press M. Weisser and N. Ban

A Translation termination and recycling (standard)

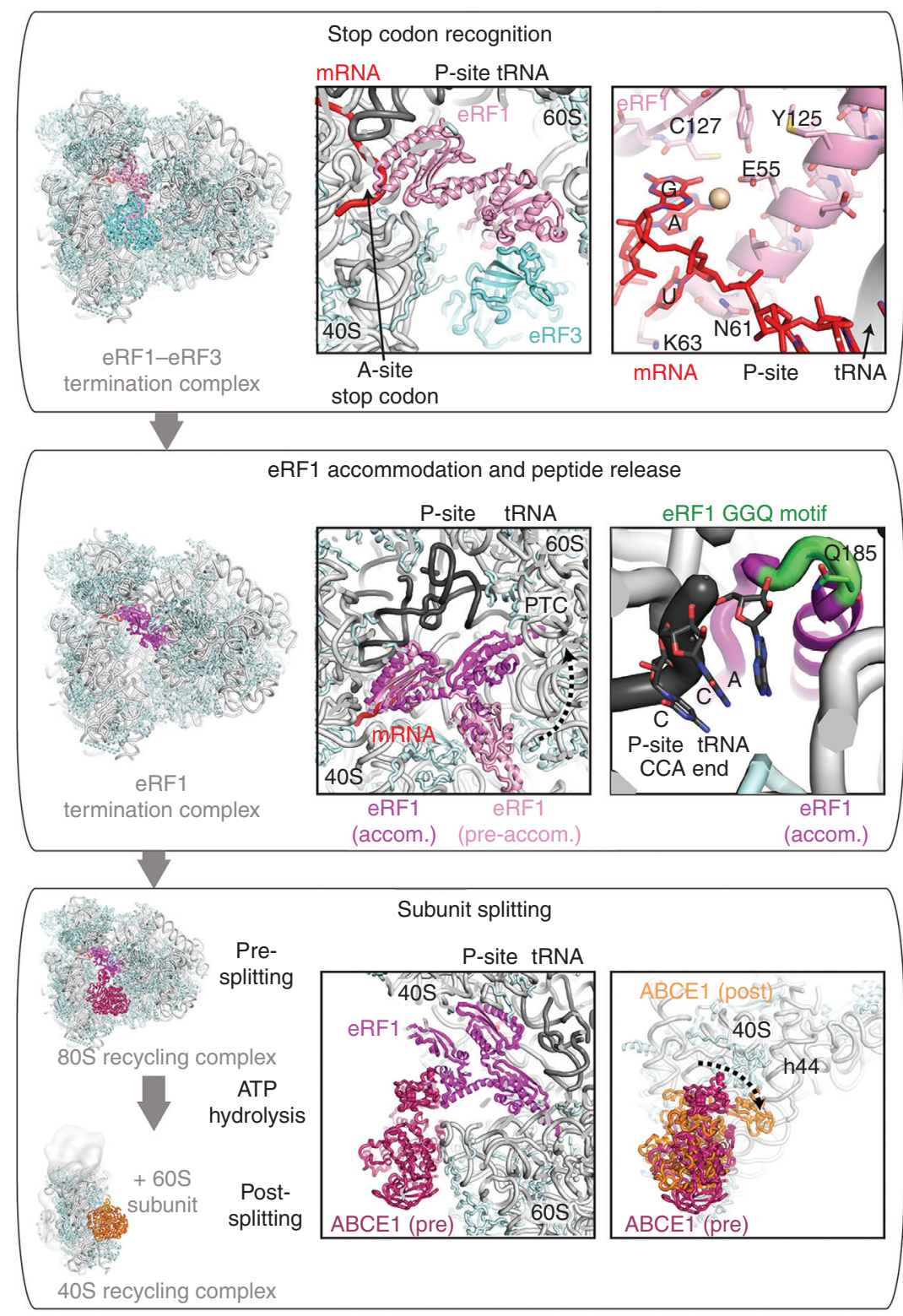

B

Translation termination and rescue

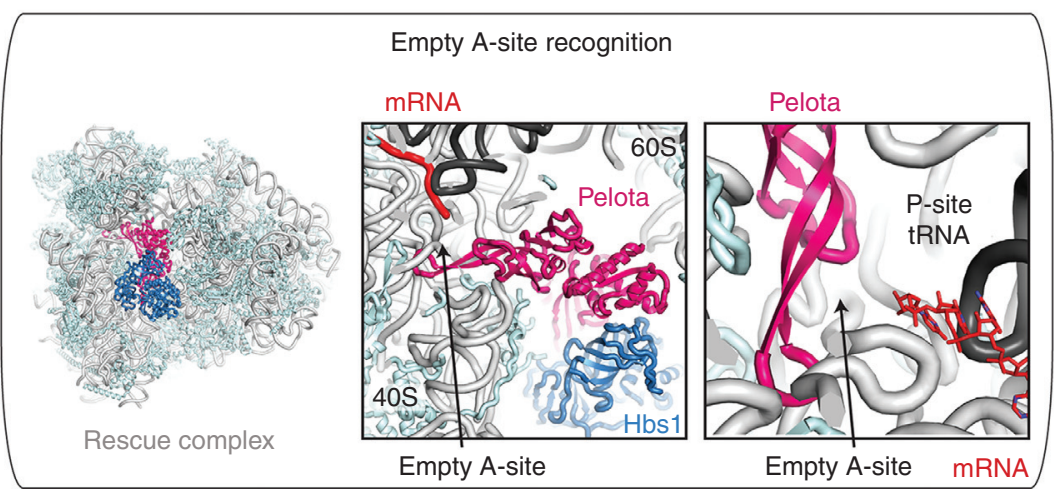

Figure 5. (See legend on following page.) 
the $18 \mathrm{~S}, 25 \mathrm{~S}$, and $5.8 \mathrm{~S}$ sequences, separated and flanked by so called internal and external transcribed spacers (ITS and ETS), whereas RNA polymerase III transcribes $5 \mathrm{~S}$ rRNA (reviewed in Nerurkar et al. 2015). The first r-proteins and assembly factors assemble cotranscriptionally onto the pre-35S rRNA and assist its folding process.

A central intermediate in ribosome biogenesis is the 5-MDa 90S preribosome or SSU processome, which encompasses 70 nonribosomal assembly factors and several small nucleolar RNAs (snoRNAs) that are organized into U3 snoRNP (small nucleolar ribonucleoprotein), UTP-A, UTPB, UTP-C, Mpp10-Imp3-Imp4, and Bms1-Rcl1 subcomplexes (Kornprobst et al. 2016; Barandun et al. 2017). These factors modify (e.g., methylate and pseudouridinylate) and successively trim the nascent $35 \mathrm{~S}$ pre-rRNA from the $5^{\prime}$ end ( $\mathrm{A}_{0}$ and $\mathrm{A}_{1}$ cleavage) to remove the $5^{\prime}$-ETS sequence (Fig. 6) (reviewed in Gerhardy et al. 2014; Nerurkar et al. 2015).

UTP-A and UTP-B are complexes of seven and six proteins, respectively, and among the earliest modules to assemble on the 5' ETS of the nascent RNA transcript. UTP-A binds the rRNA first and then recruits UTP-B and U3 snoRNP, which also interacts with middle regions of the nascent 18S rRNA (Hunziker et al. 2016). They all act as chaperones and stabilize the initial fold of the nascent rRNA and guide subsequent cleavage steps (Hunziker et al. 2016). The third rRNA cleavage, thought to be mediated by the nuclease Utp24 (a pilus retraction protein amino terminal [PIN]-type nucleus) and takes place within ITS1 (A2 cleavage) (Wells et al. 2016). It separates the pre-20S rRNA that is part of the pre-40S particle from the pre-27S rRNA that is found in the pre-60S particle (Trapman et al. 1975). From here, pre-40S and pre-60S particles follow separate maturation pathways (Fig. 6). The pre-60S associates with the $5 \mathrm{~S}$ RNP and undergoes at least three nucleolar processing steps including the $5^{\prime}$ trimming of the $27 \mathrm{~S}$ pre-rRNA before transitioning to the nucleoplasm (reviewed in Nerurkar et al. 2015).

Two intermediates of the nucleoplasmic pre-60S maturation pathway have been structurally characterized in greater detail thus far: The "early Arx1 particle" (Wu et al. 2016) and the "late Rea1 particle" (Fig. 6) (Barrio-Garcia et al. 2016). In the early Arx1 particle, the endonucleolytic cleavage of ITS2, which separates the sequence of the $5.8 \mathrm{~S}$ rRNA from the 25S rRNA by nuclease Las1, has not yet occurred. Therefore, the early Arx1 particle still displays the "foot structure" associated with ITS2 (comprising biogenesis factors Nop15, Cic1, Nop7, Rlp7, and Nop53) (Wu et al. 2016), which is lacking in the Real complex where ITS2 removal has been completed (Fig. 6) (Barrio-Garcia et al. 2016).

The two particles also differ in the positioning of the $5 \mathrm{~S}$ $\mathrm{RNP}$ at the CP that includes the A-site finger region (Leidig et al. 2014). In the early Arxl particle (Wu et al. 2016), the $5 \mathrm{~S} R N P$ is rotated by $180^{\circ}$ compared with the Real particle, in which it adopts its mature position (Fig. 6) (Leidig et al. 2014; Barrio-Garcia et al. 2016). The dynein-related ATPase Real is one of the three AAA-type ATPases that guide pre$60 \mathrm{~S}$ maturation and has been suggested to monitor the correct positioning of the $5 \mathrm{~S} \mathrm{RNP}$ and the associated $\mathrm{CP}$ remodeling (Bassler et al. 2010). Its ATPase activity mediates the release of GTPase Nog2 from the complex, which allows nuclear export factor Nmd3 to bind. Thus, Rea1mediated release of biogenesis factors ensures directionality of pre-60S maturation and serves as a maturation checkpoint before nuclear export (Bassler et al. 2010).

In contrast to the pre-60S, the pre-40S is rather rapidly exported to the cytoplasm and does not acquire many additional factors before being exported: The kinase Hrr25, ATPase Rio2, nuclease Nob1, and factors Enp1, Ltv1, and Tsr1 are assembled already in the nuclear preribosome and remain associated with the particle throughout the nuclear export process (Schäfer et al. 2003).

Pre-60S and pre-40S use a set of shared export factors, such as Crm1 or Mex67/Mtr2 and Rrp12. However, there are also subunit-specific export factors that facilitate the transport of the particles across the nuclear pore complex. Nmd3, Bud20, Ecm1, and Arx1 act as export factors for the pre-60S, whereas Yrb2 (RanBP3) appears to be involved in

Figure 5. Eukaryotic translation termination. (A) All three commonly used stop codons are being recognized by eukaryotic release factor 1 (eRF1) that binds in complex with GTPase eRF3 such that its $\mathrm{N}$ domain, harboring the conserved sequence motif NIKS (residues 61 to 64), reaches into the A-site, where it stabilizes stop codon bases 2 and 3 in a stacked conformation such that they can establish hydrogen bonds with glutamate residue 55 (Glu55) (see closeup, top panel). After eRF3-GDP release from the complex, ABCE1 can bind eRF1 and the 40S stimulating eRF1's peptide release activity, which is mediated via the universally conserved GGQ motif in the PTC of the 60S (close-up, middle panel). $\mathrm{ABCE} 1$ is an ATPase that splits the $80 \mathrm{~S}$ ribosome in $60 \mathrm{~S}$ and $40 \mathrm{~S}$ subunits through several cycles of ATP hydrolysis. In the released $40 \mathrm{~S}$ complex, the iron-sulfur (Fe-S) cluster-containing domain of ABCE1 has moved and adopts a position on helix 44 that is incompatible with $60 \mathrm{~S}$ association (bottom panel). (B) Vacant A-sites stemming from truncated mRNAs are recognized by the Hbs1-Pelota complex, which adopts a similar conformation on the ribosome as the eRF1/eRF3 complex. The insertion of Pelota into the A-site would be incompatible with the presence of a stop codon. In contrast to eRF1, Pelota possesses no peptide release activity, preventing polypeptide synthesis from truncated mRNAs. 


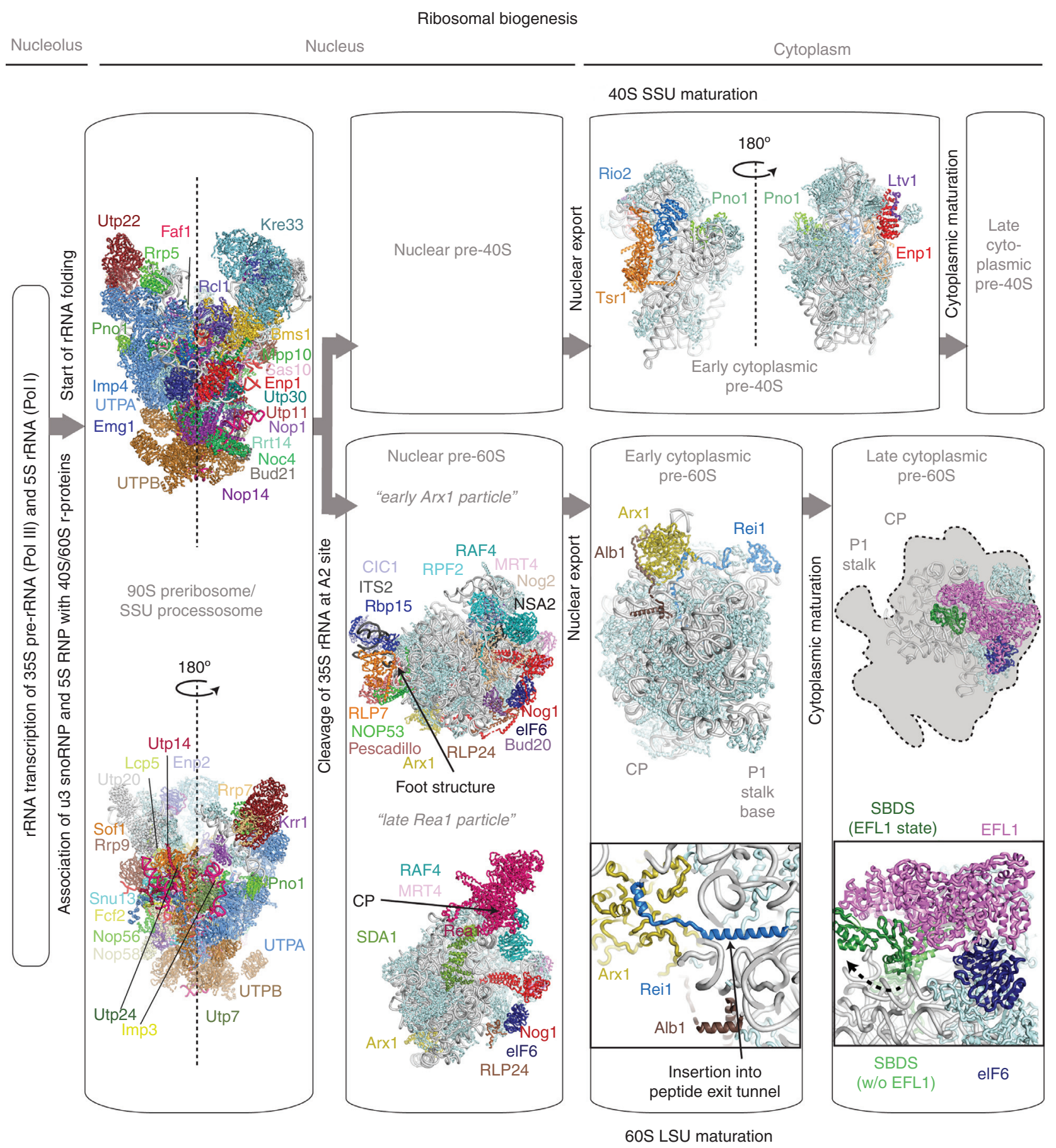

Figure 6. Eukaryotic ribosomal biogenesis. Eukaryotic ribosomal biogenesis of $40 \mathrm{~S}$ and $60 \mathrm{~S}$ subunits starts with the transcription of the $35 \mathrm{~S}$ and $5 \mathrm{~S}$ rRNA in the nucleolus and proceeds via a common precursor, the 90S preribosome (left panel), which facilitates the folding of the nascent rRNA and its cleavage into a $27 \mathrm{~S}$ pre-rRNA as part of the pre$60 \mathrm{~S}$ particle and a $20 \mathrm{~S}$ pre-rRNA as part of a pre- $40 \mathrm{~S}$ subunit. Both subunits undergo nuclear maturation steps and acquire nuclear export factors before they are exported via the nuclear pore complex to the cytoplasm. Nuclear pre60 maturation involves 5S RNP accommodation and central protuberance $(\mathrm{CP})$ rearrangement between the nuclear "early Arx1" and the "late Rea1" particles. During cytoplasmic maturation, the functional centers of the pre-60S and pre-40S are proofread. The 60S peptide exit tunnel is probed by Reil and the sarcin-ricin loop (SRL) by SBDS/eIF6, whereas the proofreading of the $40 \mathrm{~S}$ decoding center and the $40 \mathrm{~S}$ beak involves Rio2/Tsr1/Dim1 and Enp1/Ltv1, respectively. Cytoplasmic pre- $40 \mathrm{~S}$ maturation also comprises the cleavage of $20 \mathrm{~S}$ pre-rRNA into mature $18 \mathrm{~S}$ rRNA and release of export and assembly factors. 
pre-40S export (reviewed in Gerhardy et al. 2014; Nerurkar et al. 2015).

Cytoplasmic maturation steps involve the release of nuclear export factors as well as functional maturation checkpoints of the immature subunits. For example, the release of the Arx1 export factor from the pre-60S involves the cytoplasmic zinc-finger protein Reil (Meyer et al. 2010), the Jdomain protein Jjj1 (Meyer et al. 2010), and the ATPase Ssa and stimulates proper formation of a functional peptide exit tunnel (Greber et al. 2012). The structure of the cytoplasmic Arx1-Alb1-Rei1 pre-60S complex revealed that the carboxy-terminal part of Reil enters the ribosomal tunnel to check its integrity; however, when this is not possible the maturation of the pre-60S subunit is arrested and Arx1 is not released (Fig. 6) (Greber et al. 2016).

The last cytoplasmic maturation step of the pre-60S subunit includes release of eIF6, which binds to the pre$60 \mathrm{~S}$ already in the nucleus (Basu et al. 2001). eIF6 release is thought to be coupled to the proofreading of the SRL because the factor binds to the SRL on the subunit interface (Klinge et al. 2011). Dissociation of eIF6 is facilitated by EF-G/EF-2 homolog EFL1 and Shwachman-BodianDiamond syndrome protein (SBDS) (Fig. 6) (Weis et al. 2015). eIF6 release frees the $60 \mathrm{~S}$ subunit interface and therefore allows the proofread $60 \mathrm{~S}$ subunit to engage in translation.

Cytoplasmic maturation of the pre-40S subunit is governed by ribosomal assembly factors Tsr1, Ltv1, Enp1, Dim1, Dim2 (Pno1), Nob1, Rio2, and kinase Hrr25 and involves large-scale conformational rearrangements of the rRNA around the mRNA entry channel, the 40S beak, and helix 44. These rearrangements are coupled to proof-reading of the decoding center and ultimately to the cleavage of the 20 S pre-rRNA to yield the mature $18 \mathrm{~S}$ rRNA (D cleavage) (Scaiola et al. 2018).

Dim1 is a rRNA methylase that methylates the top of helix 44 on the pre-40S subunit. Upon Dim1 dissociation, helix 44 and the decoding center bases relocate closer to their positions in the mature subunit (Scaiola et al. 2018). Structures of the cytoplasmic pre-40S have revealed that Hrr25 kinase-triggered release of assembly factors Ltv1 and Enp1 allows the beak to adopt its mature conformation (Fig. 6) (Scaiola et al. 2018), whereas GTPase-like protein Tsr1 and ATPase Rio2 monitor A-site formation and prevent subunit association (Fig. 6) (Heuer et al. 2017a; Scaiola et al. 2018). Upon changes in the beak area and release of Tsr1 and Rio2 from the subunit interface area, helix 44 can adopt its mature conformation. This conformational change in the rRNA is propagated to the platform area where Pnol is bound (Heuer et al. 2017a; Scaiola et al. 2018). Movement or dissociation of Pnol is presumably triggered by conformational changes in the rRNA and aided by the cytoplasmic GTPase Fun12 (eIF5B) as well as the association with a mature $60 \mathrm{~S}$ subunit into a so-called 80S-like particle (Turowski et al. 2014). It is a prerequisite for the final cleavage of the 20S pre-rRNA by the Nob1 endonuclease (Heuer et al. 2017a), yielding mature translation-competent ribosomal subunits.

\section{FUTURE CHALLENGES}

Although our understanding of eukaryotic translation has increased dramatically in recent years, there are still many exciting unanswered questions in the field, particularly with respect to translational control, translation initiation, ribosome assembly, and targeting of proteins to different cellular compartments. Despite the advances in cryo-EM methodology, some of the processes such as the $5^{\prime}$-UTR scanning, may involve continuous structural transitions and may therefore be better suited for structure-based experiments aimed at investigating dynamic aspects of the process. Furthermore, some of the ribosomal complexes may involve factors like eIF3 or eIF4 that exert their function through flexible attachments and connective tethers. To reveal the network of such interactions, hybrid structural biology approaches that involve cryo-EM, cross-linking, mass spectrometry, and X-ray crystallography combined with integrative computational modeling are likely to be used. Another challenge lies in studying ribosomal complexes with a high degree of compositional and conformational heterogeneity, such as ribosomal biogenesis intermediates, in which trapping and purification of native intermediates can be achieved by genetic manipulation. Considering that the repertoire of tools and methods at our disposal for studying molecular structure and function has never been greater, a new generation of scientists with interdisciplinary expertise will be in an excellent position to tackle the unsolved mysteries of the protein synthesis machinery.

\section{REFERENCES}

Acker MG, Shin BS, Dever TE, Lorsch JR. 2006. Interaction between eukaryotic initiation factors $1 \mathrm{~A}$ and $5 \mathrm{~B}$ is required for efficient ribosomal subunit joining. J Biol Chem 281: 8469-8475.

Agirrezabala X, Lei J, Brunelle JL, Ortiz-Meoz RF, Green R, Frank J. 2008. Visualization of the hybrid state of tRNA binding promoted by spontaneous ratcheting of the ribosome. Mol Cell 32: 190-197.

Algire MA, Maag D, Lorsch JR. 2005. Pi release from eIF2, not GTP hydrolysis, is the step controlled by start-site selection during eukaryotic translation initiation. Mol Cell 20: 251-262.

Alkalaeva EZ, Pisarev AV, Frolova LY, Kisselev LL, Pestova TV. 2006. In vitro reconstitution of eukaryotic translation reveals cooperativity between release factors eRF1 and eRF3. Cell 125: 1125-1136.

Anger AM, Armache JP, Berninghausen O, Habeck M, Subklewe M, Wilson DN, Beckmann R. 2013. Structures of the human and Drosophila $80 \mathrm{~S}$ ribosome. Nature 497: 80-85. 
Aylett CH, Boehringer D, Erzberger JP, Schaefer T, Ban N. 2015. Structure of a yeast 40S-eIF1-eIF1A-eIF3-eIF3j initiation complex. Nat Struct Mol Biol 22: 269-271.

Bai XC, McMullan G, Scheres SH. 2015. How cryo-EM is revolutionizing structural biology. Trends Biochem Sci 40: 49-57.

Ban N, Beckmann R, Cate JH, Dinman JD, Dragon F, Ellis SR, Lafontaine DL, Lindahl L, Liljas A, Lipton JM, et al. 2014. A new system for naming ribosomal proteins. Curr Opin Struct Biol 24: 165-169.

Barandun J, Chaker-Margot M, Hunziker M, Molloy KR, Chait BT, Klinge S. 2017. The complete structure of the small-subunit processome. Nat Struct Mol Biol 24: 944-953.

Barrio-Garcia C, Thoms M, Flemming D, Kater L, Berninghausen O, Bassler J, Beckmann R, Hurt E. 2016. Architecture of the Rix1-Rea1 checkpoint machinery during pre-60S-ribosome remodeling. Nat Struct Mol Biol 23: 37-44.

Bassler J, Kallas M, Pertschy B, Ulbrich C, Thoms M, Hurt E. 2010. The AAA-ATPase Rea1 drives removal of biogenesis factors during multiple stages of 60S ribosome assembly. Mol Cell 38: 712-721.

Basu U, Si K, Warner JR, Maitra U. 2001. The Saccharomyces cerevisiae TIF6 gene encoding translation initiation factor 6 is required for $60 \mathrm{~S}$ ribosomal subunit biogenesis. Mol Cell Biol 21: 1453-1462.

Ben-Shem A, Garreau de Loubresse N, Melnikov S, Jenner L, Yusupova G, Yusupov M. 2011. The structure of the eukaryotic ribosome at $3.0 \AA$ resolution. Science 334: 1524-1529.

Bieniossek C, Schutz P, Bumann M, Limacher A, Uson I, Baumann U. 2006. The crystal structure of the carboxy-terminal domain of human translation initiation factor eIF5. J Mol Biol 360: 457-465.

Brown A, Shao S, Murray J, Hegde RS, Ramakrishnan V. 2015. Structural basis for stop codon recognition in eukaryotes. Nature 524: 493-496.

Budkevich T, Giesebrecht J, Altman RB, Munro JB, Mielke T, Nierhaus KH, Blanchard SC, Spahn CM. 2011. Structure and dynamics of the mammalian ribosomal pretranslocation complex. Mol Cell 44: 214-224.

Budkevich TV, Giesebrecht J, Behrmann E, Loerke J, Ramrath DJ, Mielke T, Ismer J, Hildebrand PW, Tung CS, Nierhaus KH, et al. 2014. Regulation of the mammalian elongation cycle by subunit rolling: A eukaryotic-specific ribosome rearrangement. Cell 158: 121-131.

Calvo SE, Pagliarini DJ, Mootha VK. 2009. Upstream open reading frames cause widespread reduction of protein expression and are polymorphic among humans. Proc Natl Acad Sci 106: 7507-7512.

Cheung YN, Maag D, Mitchell SF, Fekete CA, Algire MA, Takacs JE, Shirokikh N, Pestova T, Lorsch JR, Hinnebusch AG. 2007. Dissociation of eIF1 from the 40S ribosomal subunit is a key step in start codon selection in vivo. Genes Dev 21: 1217-1230.

Costantino DA, Pfingsten JS, Rambo RP, Kieft JS. 2008. tRNA-mRNA mimicry drives translation initiation from a viral IRES. Nat Struct Mol Biol 15: 57-64.

Crepin T, Shalak VF, Yaremchuk AD, Vlasenko DO, McCarthy A, Negrutskii BS, Tukalo MA, El'skaya AV. 2014. Mammalian translation elongation factor eEF1A2: X-ray structure and new features of GDP/ GTP exchange mechanism in higher eukaryotes. Nucleic Acids Res 42: 12939-12948.

Crick FH. 1966. Codon-anticodon pairing: The wobble hypothesis. J Mol Biol 19: 548-555.

Das S, Maitra U. 2001. Functional significance and mechanism of eIF5promoted GTP hydrolysis in eukaryotic translation initiation. Prog Nucleic Acid Res Mol Biol 70: 207-231.

de Breyne S, Yu Y, Unbehaun A, Pestova TV, Hellen CU. 2009. Direct functional interaction of initiation factor eIF4G with type 1 internal ribosomal entry sites. Proc Natl Acad Sci 106: 9197-9202.

Diaconu M, Kothe U, Schlunzen F, Fischer N, Harms JM, Tonevitsky AG, Stark H, Rodnina MV, Wahl MC. 2005. Structural basis for the function of the ribosomal L7/12 stalk in factor binding and GTPase activation. Cell 121: 991-1004.

Erzberger JP, Stengel F, Pellarin R, Zhang S, Schaefer T, Aylett CH, Cimermancic P, Boehringer D, Sali A, Aebersold R, et al. 2014. Molecular architecture of the 40SeIF1eIF3 translation initiation complex. Cell 158: $1123-1135$.
Fei J, Kosuri P, MacDougall DD, Gonzalez RL Jr. 2008. Coupling of ribosomal L1 stalk and tRNA dynamics during translation elongation. Mol Cell 30: 348-359.

Fekete CA, Mitchell SF, Cherkasova VA, Applefield D, Algire MA, Maag D, Saini AK, Lorsch JR, Hinnebusch AG. 2007. N- and C-terminal residues of eIF1A have opposing effects on the fidelity of start codon selection. EMBO J 26: 1602-1614.

Fernandez IS, Bai XC, Hussain T, Kelley AC, Lorsch JR, Ramakrishnan V, Scheres SHW. 2013. Molecular architecture of a eukaryotic translational initiation complex. Science 342: 1240585.

Fringer JM, Acker MG, Fekete CA, Lorsch JR, Dever TE. 2007. Coupled release of eukaryotic translation initiation factors $5 \mathrm{~B}$ and $1 \mathrm{~A}$ from $80 \mathrm{~S}$ ribosomes following subunit joining. Mol Cell Biol 27: 2384-2397.

Frolova LY, Tsivkovskii RY, Sivolobova GF, Oparina NY, Serpinsky OI, Blinov VM, Tatkov SI, Kisselev LL. 1999. Mutations in the highly conserved GGQ motif of class 1 polypeptide release factors abolish ability of human eRF1 to trigger peptidyl-tRNA hydrolysis. RNA 5: 1014-1020.

Gao H, Ayub MJ, Levin MJ, Frank J. 2005. The structure of the $80 \mathrm{~S}$ ribosome from Trypanosoma cruzi reveals unique rRNA components. Proc Natl Acad Sci 102: 10206-10211.

Gerhardy S, Menet AM, Pena C, Petkowski JJ, Panse VG. 2014. Assembly and nuclear export of pre-ribosomal particles in budding yeast. Chromosoma 123: 327-344.

Gogala M, Becker T, Beatrix B, Armache JP, Barrio-Garcia C, Berninghausen O, Beckmann R. 2014. Structures of the Sec61 complex engaged in nascent peptide translocation or membrane insertion. Nature 506: 107-110.

Greber BJ, Boehringer D, Montellese C, Ban N. 2012. Cryo-EM structures of Arx1 and maturation factors Rei1 and Jjj1 bound to the 60S ribosomal subunit. Nat Struct Mol Biol 19: 1228-1233.

Greber BJ, Gerhardy S, Leitner A, Leibundgut M, Salem M, Boehringer D, Leulliot N, Aebersold R, Panse VG, Ban N. 2016. Insertion of the biogenesis factor Reil probes the ribosomal tunnel during $60 \mathrm{~S}$ maturation. Cell 164: 91-102.

Hashem Y, des Georges A, Dhote V, Langlois R, Liao HY, Grassucci RA, Hellen CU, Pestova TV, Frank J. 2013a. Structure of the mammalian ribosomal $43 \mathrm{~S}$ preinitiation complex bound to the scanning factor DHX29. Cell 153: 1108-1119.

Hashem Y, des Georges A, Dhote V, Langlois R, Liao HY, Grassucci RA, Pestova TV, Hellen CU, Frank J. 2013b. Hepatitis-C-virus-like internal ribosome entry sites displace eIF3 to gain access to the $40 \mathrm{~S}$ subunit. Nature 503: 539-543.

Hashem Y, des Georges A, Fu J, Buss SN, Jossinet F, Jobe A, Zhang Q, Liao HY, Grassucci RA, Bajaj C, et al. 2013c. High-resolution cryo-electron microscopy structure of the Trypanosoma brucei ribosome. Nature 494: 385-389.

Hellens RP, Brown CM, Chisnall MA, Waterhouse PM, Macknight RC. 2016. The emerging world of small ORFs. Trends Plant Sci 21: 317-328.

Heuer A, Thomson E, Schmidt C, Berninghausen O, Becker T, Hurt E, Beckmann R. 2017a. Cryo-EM structure of a late pre-40S ribosomal subunit from Saccharomyces cerevisiae. Elife 6: e30189.

Heuer A, Gerovac M, Schmidt C, Trowitzsch S, Preis A, Kotter P, Berninghausen O, Becker T, Beckmann R, Tampe R. 2017b. Structure of the $40 \mathrm{~S}-\mathrm{ABCE} 1$ post-splitting complex in ribosome recycling and translation initiation. Nat Struct Mol Biol 24: 453-460.

Hinnebusch AG. 2011. Molecular mechanism of scanning and start codon selection in eukaryotes. Microbiol Mol Biol Rev 75: 434-467, first page of Table of Contents.

Hinnebusch AG. 2014. The scanning mechanism of eukaryotic translation initiation. Annu Rev Biochem 83: 779-812.

Hinnebusch AG, Ivanov IP, Sonenberg N. 2016. Translational control by $5^{\prime}$-untranslated regions of eukaryotic mRNAs. Science 352: 1413-1416.

Hunziker M, Barandun J, Petfalski E, Tan D, Delan-Forino C, Molloy KR, Kim KH, Dunn-Davies H, Shi Y, Chaker-Margot M, et al. 2016. UtpA and UtpB chaperone nascent pre-ribosomal RNA and U3 snoRNA to initiate eukaryotic ribosome assembly. Nat Commun 7: 12090.

Hussain T, Llácer JL, Fernandez IS, Munoz A, Martin-Marcos P, Savva CG, Lorsch JR, Hinnebusch AG, Ramakrishnan V. 2014. Structural 
changes enable start codon recognition by the eukaryotic translation initiation complex. Cell 159: 597-607.

Jackson RJ, Hellen CU, Pestova TV. 2012. Termination and post-termination events in eukaryotic translation. Adv Protein Chem Struct Biol 86: 45-93.

Jivotovskaya AV, Valasek L, Hinnebusch AG, Nielsen KH. 2006. Eukaryotic translation initiation factor 3 (eIF3) and eIF2 can promote mRNA binding to $40 \mathrm{~S}$ subunits independently of eIF4G in yeast. Mol Cell Biol 26: $1355-1372$.

Kapp LD, Kolitz SE, Lorsch JR. 2006. Yeast initiator tRNA identity elements cooperate to influence multiple steps of translation initiation. RNA 12: 751-764.

Klinge S, Voigts-Hoffmann F, Leibundgut M, Arpagaus S, Ban N. 2011. Crystal structure of the eukaryotic 60S ribosomal subunit in complex with initiation factor 6. Science 334: 941-948.

Kobayashi K, Kikuno I, Kuroha K, Saito K, Ito K, Ishitani R, Inada T, Nureki O. 2010. Structural basis for mRNA surveillance by archaeal Pelota and GTP-bound EF1 $\alpha$ complex. Proc Natl Acad Sci 107: 1757517579.

Kolitz SE, Lorsch JR. 2010. Eukaryotic initiator tRNA: Finely tuned and ready for action. FEBS Lett 584: 396-404.

Kornprobst M, Turk M, Kellner N, Cheng J, Flemming D, Kos-Braun I, Kos M, Thoms M, Berninghausen O, Beckmann R, et al. 2016. Architecture of the $90 \mathrm{~S}$ pre-ribosome: A structural view on the birth of the eukaryotic ribosome. Cell 166: 380-393.

Korostelev A, Trakhanov S, Laurberg M, Noller HF. 2006. Crystal structure of a $70 \mathrm{~S}$ ribosome-tRNA complex reveals functional interactions and rearrangements. Cell 126: 1065-1077.

Kozak M. 1986. Point mutations define a sequence flanking the AUG initiator codon that modulates translation by eukaryotic ribosomes. Cell 44: 283-292.

Lawless C, Pearson RD, Selley JN, Smirnova JB, Grant CM, Ashe MP, Pavitt GD, Hubbard SJ. 2009. Upstream sequence elements direct posttranscriptional regulation of gene expression under stress conditions in yeast. BMC Genomics 10: 7.

Lee B, Udagawa T, Singh CR, Asano K. 2007. Yeast phenotypic assays on translational control. Methods Enzymol 429: 105-137.

Leidig C, Thoms M, Holdermann I, Bradatsch B, Berninghausen O, Bange G, Sinning I, Hurt E, Beckmann R. 2014. 60S ribosome biogenesis requires rotation of the $5 \mathrm{~S}$ ribonucleoprotein particle. Nat Commun 5: 3491.

Llácer JL, Hussain T, Marler L, Aitken CE, Thakur A, Lorsch JR, Hinnebusch AG, Ramakrishnan V. 2015. Conformational differences between open and closed states of the eukaryotic translation initiation complex. Mol Cell 59: 399-412.

Locker N, Easton LE, Lukavsky PJ. 2007. HCV and CSFV IRES domain II mediate eIF2 release during 80 S ribosome assembly. EMBO J 26: $795-$ 805.

Lomakin IB, Steitz TA. 2013. The initiation of mammalian protein synthesis and mRNA scanning mechanism. Nature 500: 307-311.

Lomakin IB, Stolboushkina EA, Vaidya AT, Zhao C, Garber MB, Dmitriev SE, Steitz TA. 2017. Crystal structure of the human ribosome in complex with DENR-MCT-1. Cell Rep 20: 521-528.

Luna RE, Arthanari H, Hiraishi H, Nanda J, Martin-Marcos P, Markus MA, Akabayov B, Milbradt AG, Luna LE, Seo HC, et al. 2012. The Cterminal domain of eukaryotic initiation factor 5 promotes start codon recognition by its dynamic interplay with eIF1 and eIF2 $\beta$. Cell Rep 1: 689-702.

Marintchev A. 2013. Roles of helicases in translation initiation: A mechanistic view. Biochim Biophys Acta 1829: 799-809.

Martin-Marcos P, Nanda J, Luna RE, Wagner G, Lorsch JR, Hinnebusch AG. 2013. $\beta$-hairpin loop of eukaryotic initiation factor 1 (eIF1) mediates $40 \mathrm{~S}$ ribosome binding to regulate initiator tRNA(Met) recruitment and accuracy of AUG selection in vivo. J Biol Chem 288: 27546-27562.

Melnikov S, Ben-Shem A, Garreau de Loubresse N, Jenner L, Yusupova G, Yusupov M. 2012. One core, two shells: Bacterial and eukaryotic ribosomes. Nat Struct Mol Biol 19: 560-567.
Melnikov S, Mailliot J, Shin BS, Rigger L, Yusupova G, Micura R, Dever TE, Yusupov M. 2016. Crystal structure of hypusine-containing translation factor eIF5A bound to a rotated eukaryotic ribosome. J Mol Biol 428: $3570-3576$.

Meyer AE, Hoover LA, Craig EA. 2010. The cytosolic J-protein, Jjj1 and Reil function in the removal of the pre-60 S subunit factor Arx1.J Biol Chem 285: 961-968.

Mohammad MP, Munzarova Pondelickova V, Zeman J, Gunisova S, Valasek LS. 2017. In vivo evidence that eIF3 stays bound to ribosomes elongating and terminating on short upstream ORFs to promote reinitiation. Nucleic Acids Res 45: 2658-2674.

Nanda JS, Cheung YN, Takacs JE, Martin-Marcos P, Saini AK, Hinnebusch AG, Lorsch JR. 2009. eIF1 controls multiple steps in start codon recognition during eukaryotic translation initiation. J Mol Biol 394: 268-285.

Nerurkar P, Altvater M, Gerhardy S, Schutz S, Fischer U, Weirich C, Panse VG. 2015. Eukaryotic ribosome assembly and nuclear export. Int Rev Cell Mol Biol 319: 107-140.

Nikolov EN, Dabeva MD, Nikolov TK. 1983. Turnover of ribosomes in regenerating rat liver. Int J Biochem 15: 1255-1260.

Nissen P, Hansen J, Ban N, Moore PB, Steitz TA. 2000. The structural basis of ribosome activity in peptide bond synthesis. Science 289: 920-930.

Ogle JM, Brodersen DE, Clemons WM Jr, Tarry MJ, Carter AP, Ramakrishnan V. 2001. Recognition of cognate transfer RNA by the 30S ribosomal subunit. Science 292: 897-902.

Ogle JM, Murphy FV, Tarry MJ, Ramakrishnan V. 2002. Selection of tRNA by the ribosome requires a transition from an open to a closed form. Cell 111: 721-732.

Olsen DS, Savner EM, Mathew A, Zhang F, Krishnamoorthy T, Phan L, Hinnebusch AG. 2003. Domains of eIF1A that mediate binding to eIF2, eIF3 and eIF5B and promote ternary complex recruitment in vivo. EMBO J 22: 193-204.

Otto GA, Puglisi JD. 2004. The pathway of HCV IRES-mediated translation initiation. Cell 119: 369-380.

Pesole G, Mignone F, Gissi C, Grillo G, Licciulli F, Liuni S. 2001. Structural and functional features of eukaryotic mRNA untranslated regions. Gene 276: 73-81.

Pestova TV, Kolupaeva VG. 2002. The roles of individual eukaryotic translation initiation factors in ribosomal scanning and initiation codon selection. Genes Dev 16: 2906-2922.

Pisarev AV, Skabkin MA, Pisareva VP, Skabkina OV, Rakotondrafara AM, Hentze MW, Hellen CU, Pestova TV. 2010. The role of ABCE1 in eukaryotic posttermination ribosomal recycling. Mol Cell 37: 196-210.

Pisareva VP, Pisarev AV, Komar AA, Hellen CU, Pestova TV. 2008. Translation initiation on mammalian mRNAs with structured $5^{\prime}$ UTRs requires DExH-box protein DHX29. Cell 135: 1237-1250.

Poyry TA, Kaminski A, Jackson RJ. 2004. What determines whether mammalian ribosomes resume scanning after translation of a short upstream open reading frame? Genes Dev 18: 62-75.

Preis A, Heuer A, Barrio-Garcia C, Hauser A, Eyler DE, Berninghausen O, Green R, Becker T, Beckmann R. 2014. Cryoelectron microscopic structures of eukaryotic translation termination complexes containing eRF1-eRF3 or eRF1-ABCE1. Cell Rep 8: 59-65.

Quade N, Boehringer D, Leibundgut M, van den Heuvel J, Ban N. 2015. Cryo-EM structure of hepatitis C virus IRES bound to the human ribosome at 3.9-Å resolution. Nat Commun 6: 7646.

Rabl J, Leibundgut M, Ataide SF, Haag A, Ban N. 2011. Crystal structure of the eukaryotic $40 \mathrm{~S}$ ribosomal subunit in complex with initiation factor 1. Science 331: 730-736.

Ratje AH, Loerke J, Mikolajka A, Brünner M, Hildebrand PW, Starosta AL, Dönhöfer A, Connell SR, Fucini P, Mielke T, et al. 2010. Head swivel on the ribosome facilitates translocation by means of intra-subunit tRNA hybrid sites. Nature 468: 713-716.

Redondo N, Garcia-Moreno M, Sanz MA, Carrasco L. 2013. Translation of viral mRNAs that do not require eIF4E is blocked by the inhibitor 4EGI-1. Virology 444: 171-180. 
Reibarkh M, Yamamoto Y, Singh CR, del Rio F, Fahmy A, Lee B, Luna RE, Ii M, Wagner G, Asano K. 2008. Eukaryotic initiation factor (eIF) 1 carries two distinct eIF5-binding faces important for multifactor assembly and AUG selection. J Biol Chem 283: 1094-1103.

Roll-Mecak A, Alone P, Cao C, Dever TE, Burley SK. 2004. X-ray structure of translation initiation factor eIF2 $\gamma$ : Implications for tRNA and eIF2 $\alpha$ binding. J Biol Chem 279: 10634-10642.

Saini AK, Nanda JS, Lorsch JR, Hinnebusch AG. 2010. Regulatory elements in eIF1A control the fidelity of start codon selection by modulating tRNA(i)(Met) binding to the ribosome. Genes Dev 24: 97-110.

Scaiola A, Pena C, Weisser M, Bohringer D, Leibundgut M, KlingaufNerurkar P, Gerhardy S, Panse VG, Ban N. 2018. Structure of a eukaryotic cytoplasmic pre-40S ribosomal subunit. EMBO J 37: e98499.

Schäfer T, Strauss D, Petfalski E, Tollervey D, Hurt E. 2003. The path from nucleolar $90 \mathrm{~S}$ to cytoplasmic $40 \mathrm{~S}$ pre-ribosomes. EMBO J 22: 13701380.

Schleich S, Strassburger K, Janiesch PC, Koledachkina T, Miller KK, Haneke K, Cheng YS, Kuchler K, Stoecklin G, Duncan KE, et al. 2014. DENR-MCT-1 promotes translation re-initiation downstream of uORFs to control tissue growth. Nature 512: 208-212.

Schmeing TM, Ramakrishnan V. 2009. What recent ribosome structures have revealed about the mechanism of translation. Nature 461: 12341242.

Schmeing TM, Huang KS, Strobel SA, Steitz TA. 2005. An induced-fit mechanism to promote peptide bond formation and exclude hydrolysis of peptidyl-tRNA. Nature 438: 520-524.

Schmitt E, Naveau M, Mechulam Y. 2010. Eukaryotic and archaeal translation initiation factor 2: A heterotrimeric tRNA carrier. FEBS Lett 584: 405-412.

Schmitt E, Panvert M, Lazennec-Schurdevin C, Coureux PD, Perez J, Thompson A, Mechulam Y. 2012. Structure of the ternary initiation complex aIF2-GDPNP-methionylated initiator tRNA. Nat Struct Mol Biol 19: 450-454.

Shalev-Benami M, Zhang Y, Matzov D, Halfon Y, Zackay A, Rozenberg H, Zimmerman E, Bashan A, Jaffe CL, Yonath A, et al. 2016. 2.8-Å cryoEM structure of the large ribosomal subunit from the eukaryotic parasite Leishmania. Cell Rep 16: 288-294.

Shao S, Murray J, Brown A, Taunton J, Ramakrishnan V, Hegde RS. 2016. Decoding mammalian ribosome-mRNA states by translational GTPase complexes. Cell 167: 1229-1240.e15.

Skabkin MA, Skabkina OV, Dhote V, Komar AA, Hellen CU, Pestova TV. 2010. Activities of Ligatin and MCT-1/DENR in eukaryotic translation initiation and ribosomal recycling. Genes Dev 24: 1787-1801.

Skabkin MA, Skabkina OV, Hellen CU, Pestova TV. 2013. Reinitiation and other unconventional posttermination events during eukaryotic translation. Mol Cell 51: 249-264.

Spahn CMT, Gomez-Lorenzo MG, Grassucci RA, Jorgensen R, Andersen GR, Beckmann R, Penczek PA, Ballesta JPG, Frank J. 2004. Domain movements of elongation factor eEF2 and the eukaryotic $80 \mathrm{~S}$ ribosome facilitate tRNA translocation. EMBO J 23: 1008-1019.

Sun M, Li W, Blomqvist K, Das S, Hashem Y, Dvorin JD, Frank J. 2015. Dynamical features of the Plasmodium falciparum ribosome during translation. Nucleic Acids Res 43: 10515-10524.

Svidritskiy E, Brilot AF, Koh CS, Grigorieff N, Korostelev AA. 2014. Structures of yeast $80 \mathrm{~S}$ ribosome-tRNA complexes in the rotated and nonrotated conformations. Structure 22: 1210-1218.

Takyar S, Hickerson RP, Noller HF. 2005. mRNA helicase activity of the ribosome. Cell 120: 49-58.

Taylor DJ, Nilsson J, Merrill AR, Andersen GR, Nissen P, Frank J. 2007. Structures of modified eEF2 80 S ribosome complexes reveal the role of GTP hydrolysis in translocation. EMBO J 26: 2421-2431.

Terenin IM, Akulich KA, Andreev DE, Polyanskaya SA, Shatsky IN, Dmitriev SE. 2016. Sliding of a 43 S ribosomal complex from the recognized AUG codon triggered by a delay in eIF2-bound GTP hydrolysis. Nucleic Acids Res 44: 1882-1893.
Trapman J, Retel J, Planta RJ. 1975. Ribosomal precursor particles from yeast. Exp Cell Res 90: 95-104.

Turowski TW, Lebaron S, Zhang E, Peil L, Dudnakova T, Petfalski E, Granneman S, Rappsilber J, Tollervey D. 2014. Rio1 mediates ATPdependent final maturation of $40 \mathrm{~S}$ ribosomal subunits. Nucleic Acids Res 42: 12189-12199.

van den Elzen AM, Schuller A, Green R, Seráphin B. 2014. Dom34-Hbs1 mediated dissociation of inactive $80 \mathrm{~S}$ ribosomes promotes restart of translation after stress. EMBO J 33: 265-276.

Vassilenko KS, Alekhina OM, Dmitriev SE, Shatsky IN, Spirin AS. 2011. Unidirectional constant rate motion of the ribosomal scanning particle during eukaryotic translation initiation. Nucleic Acids Res 39: 55555567.

Villa N, Do A, Hershey JWB, Fraser CS. 2013. Human eukaryotic initiation factor $4 \mathrm{G}$ (eIF4G) protein binds to eIF3c, -d, and -e to promote mRNA recruitment to the ribosome. J Biol Chem 288: 3293232940.

Voigts-Hoffmann F, Klinge S, Ban N. 2012. Structural insights into eukaryotic ribosomes and the initiation of translation. Curr Opin Struct Biol 22: 768-777.

Voorhees RM, Ramakrishnan V. 2013. Structural basis of the translational elongation cycle. Annu Rev Biochem 82: 203-236.

Voorhees RM, Schmeing TM, Kelley AC, Ramakrishnan V. 2010. The mechanism for activation of GTP hydrolysis on the ribosome. Science 330: $835-838$.

Voorhees RM, Fernandez IS, Scheres SHW, Hegde RS. 2014. Structure of the mammalian ribosome-Sec61 complex to 3.4 Å resolution. Cell 157: 1632-1643.

Walsh D, Mohr I. 2011. Viral subversion of the host protein synthesis machinery. Nat Rev Microbiol 9: 860-875.

Weingarten-Gabbay S, Elias-Kirma S, Nir R, Gritsenko AA, Stern-Ginossar N, Yakhini Z, Weinberger A, Segal E. 2016. Comparative genetics. Systematic discovery of cap-independent translation sequences in human and viral genomes. Science 351: aad4939.

Weis F, Giudice E, Churcher M, Jin L, Hilcenko C, Wong CC, Traynor D, Kay RR, Warren AJ. 2015. Mechanism of eIF6 release from the nascent 60 S ribosomal subunit. Nat Struct Mol Biol 22: 914-919.

Weisser M, Voigts-Hoffmann F, Rabl J, Leibundgut M, Ban N. 2013. The crystal structure of the eukaryotic $40 \mathrm{~S}$ ribosomal subunit in complex with eIF1 and eIF1A. Nat Struct Mol Biol 20: 1015-1017.

Weisser M, Schäfer T, Leibundgut M, Bohringer D, Aylett CHS, Ban N. 2017. Structural and functional insights into human re-initiation complexes. Mol Cell 67: 447-456.e7.

Wells SE, Hillner PE, Vale RD, Sachs AB. 1998. Circularization of mRNA by eukaryotic translation initiation factors. Mol Cell 2: 135-140.

Wells GR, Weichmann F, Colvin D, Sloan KE, Kudla G, Tollervey D, Watkins NJ, Schneider C. 2016. The PIN domain endonuclease Utp24 cleaves pre-ribosomal RNA at two coupled sites in yeast and humans. Nucleic Acids Res 44: 5399-5409.

Wimberly BT, Brodersen DE, Clemons WM Jr., Morgan-Warren RJ, Carter AP, Vonrhein C, Hartsch T, Ramakrishnan V. 2000. Structure of the 30S ribosomal subunit. Nature 407: 327-339.

Wu S, Tutuncuoglu B, Yan K, Brown H, Zhang Y, Tan D, Gamalinda M, Yuan Y, Li Z, Jakovljevic J, et al. 2016. Diverse roles of assembly factors revealed by structures of late nuclear pre-60S ribosomes. Nature 534: $133-137$.

Xue S, Barna M. 2012. Specialized ribosomes: A new frontier in gene regulation and organismal biology. Nat Rev Mol Cell Biol 13: 355-369.

Yu Y, Marintchev A, Kolupaeva VG, Unbehaun A, Veryasova T, Lai SC, Hong P, Wagner G, Hellen CU, Pestova TV. 2009. Position of eukaryotic translation initiation factor eIF1A on the $40 \mathrm{~S}$ ribosomal subunit mapped by directed hydroxyl radical probing. Nucleic Acids Res 37: 5167-5182.

Zhang F, Saini AK, Shin BS, Nanda J, Hinnebusch AG. 2015. Conformational changes in the P site and mRNA entry channel evoked by AUG recognition in yeast translation preinitiation complexes. Nucleic Acids Res 43: 2293-2312. 


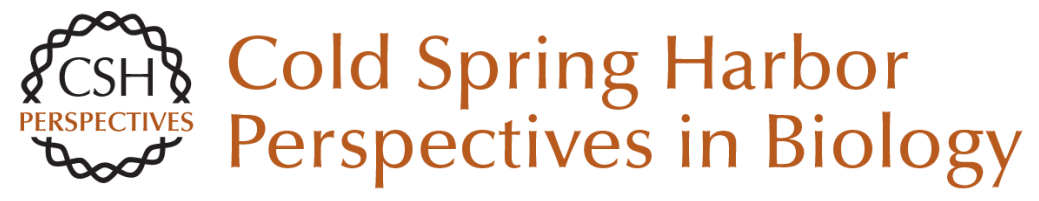

\section{Extensions, Extra Factors, and Extreme Complexity: Ribosomal Structures Provide Insights into Eukaryotic Translation}

Melanie Weisser and Nenad Ban

Cold Spring Harb Perspect Biol 2019; doi: 10.1101/cshperspect.a032367

Subject Collection RNA Worlds

Alternate RNA Structures

Marie Teng-Pei Wu and Victoria D'Souza

Approaches for Understanding the Mechanisms of Long Noncoding RNA Regulation of Gene Expression

Patrick McDonel and Mitchell Guttman

Principles and Practices of Hybridization Capture

Experiments to Study Long Noncoding RNAs That

Act on Chromatin

Matthew D. Simon and Martin Machyna

Linking RNA Sequence, Structure, and Function

on Massively Parallel High-Throughput

Sequencers

Sarah K. Denny and William J. Greenleaf

Extensions, Extra Factors, and Extreme

Complexity: Ribosomal Structures Provide

Insights into Eukaryotic Translation

Melanie Weisser and Nenad Ban

Nascent RNA and the Coordination of Splicing with Transcription

Karla M. Neugebauer

Combining Mass Spectrometry (MS) and Nuclear Magnetic Resonance (NMR) Spectroscopy for Integrative Structural Biology of Protein-RNA

Complexes

Alexander Leitner, Georg Dorn and Frédéric H.-T. Allain

For additional articles in this collection, see http://cshperspectives.cshlp.org/cgi/collection/

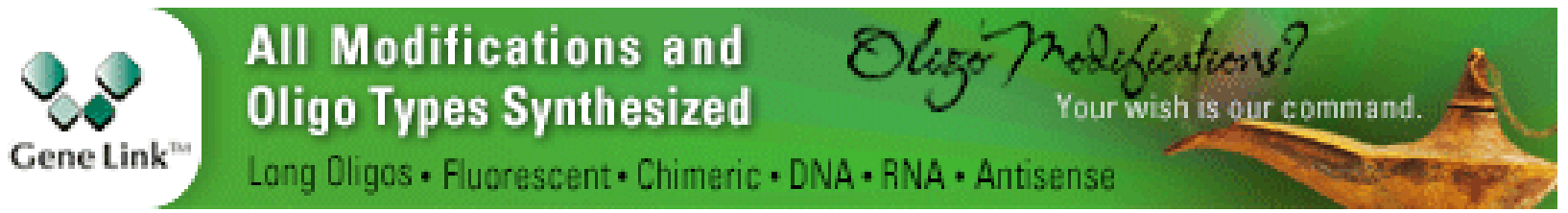

Structural Biology of Telomerase

Yaqiang Wang, Lukas Susac and Juli Feigon

Structural Insights into Nuclear pre-mRNA

Splicing in Higher Eukaryotes

Berthold Kastner, Cindy L. Will, Holger Stark, et al.

What Are 3' UTRs Doing?

Christine Mayr

Single-Molecule Analysis of Reverse

Transcriptase Enzymes

Linnea I. Jansson and Michael D. Stone

\section{CRISPR Tools for Systematic Studies of RNA \\ Regulation \\ Jesse Engreitz, Omar Abudayyeh, Jonathan}

Gootenberg, et al.

Relating Structure and Dynamics in RNA Biology Kevin P. Larsen, Junhong Choi, Arjun Prabhakar, et al.

Beyond DNA and RNA: The Expanding Toolbox of Synthetic Genetics

Alexander I. Taylor, Gillian Houlihan and Philipp Holliger

Copyright @ 2019 Cold Spring Harbor Laboratory Press; all rights reserved 
Discovering and Mapping the Modified Nucleotides That Comprise the Epitranscriptome of mRNA

Bastian Linder and Samie R. Jaffrey
Structural Basis of Nuclear pre-mRNA Splicing:

\section{Lessons from Yeast}

Clemens Plaschka, Andrew J. Newman and Kiyoshi Nagai

For additional articles in this collection, see http://cshperspectives.cshlp.org/cgi/collection/

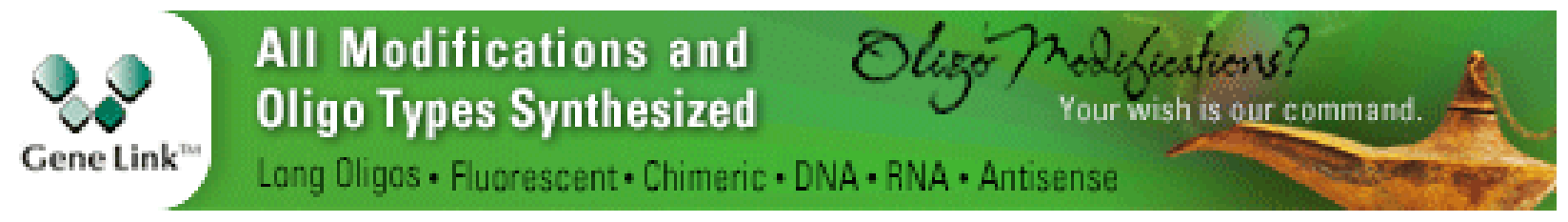

Copyright (C) 2019 Cold Spring Harbor Laboratory Press; all rights reserved 